\title{
Metal-free and transition-metal tetraferrocenylporphyrins part 1: synthesis, characterization, electronic structure, and conformational flexibility of neutral compounds $\dagger$
}

\author{
Victor N. Nemykin, ${ }^{* a}$ Pierluca Galloni, ${ }^{* b}$ Barbara Floris, ${ }^{b}$ Christopher D. Barrett, ${ }^{a}$ Ryan G. Hadt, ${ }^{a}$ \\ Roman I. Subbotin, ${ }^{a}$ Andrea G. Marrani, ${ }^{c}$ Robertino Zanoni ${ }^{c}$ and Nikolay M. Loim ${ }^{d}$
}

Received 26th March 2008, Accepted 30th May 2008

First published as an Advance Article on the web 9th July 2008

DOI: 10.1039/b805156a

$\mathrm{H}_{2} \mathrm{TFcP}[\mathrm{TFcP}=5,10,15,20$-tetraferrocenyl porphyrin(2-)] was prepared by a direct tetramerization reaction between pyrrole and ferrocene carbaldehyde in the presence of a $\mathrm{BF}_{3}$ catalyst, while the series of $\mathrm{MTFcP}(\mathrm{M}=\mathrm{Zn}, \mathrm{Ni}, \mathrm{Co}$ and $\mathrm{Cu})$ were prepared by a metallation reaction between $\mathrm{H}_{2} \mathrm{TFcP}$ and respective metal acetates. All compounds were characterized by UV-vis and MCD spectroscopy, APCI MS and MS/MS methods, high-resolution ESI MS and XPS spectroscopy. Diamagnetic compounds were additionally characterized using ${ }^{1} \mathrm{H}$ and ${ }^{13} \mathrm{C}$ NMR methods, while the presence of low-spin iron(II) centers in the neutral compounds was confirmed by Mössbauer spectroscopy and by analysis of the XPS Fe 2p peaks, revealing equivalent Fe sites. XPS additionally showed the influence on Fe $2 p$ binding energies exerted by the distinct central metal ions. The conformational flexibility of ferrocene substituents in $\mathrm{H}_{2} \mathrm{TFcP}$ and $\mathrm{MTFcP}$, was confirmed using variable-temperature NMR and computational methods. Density functional theory predicts that $\alpha, \beta, \alpha, \beta$ atropisomers with ruffled porphyrin cores represent minima on the potential energy surfaces of both $\mathrm{H}_{2} \mathrm{TFcP}$ and MTFcP. The degree of non-planarity is central-metal dependent and follows the trend: $\mathrm{ZnTFcP}<\mathrm{H}_{2} \mathrm{TFcP} \sim$ $\mathrm{CuTFcP}<\mathrm{CoTFcP}<\mathrm{NiTFcP}$. In all cases, a set of occupied, predominantly ferrocene-based molecular orbitals were found between the highest occupied and the lowest unoccupied, predominantly porphyrin-based molecular orbitals. The vertical excitation energies of $\mathrm{H}_{2} \mathrm{TFcP}$ were calculated at the TDDFT level and confirm the presence of numerous predominantly metal-to-ligand charge-transfer bands coupled via configurational interaction with expected intra-ligand $\pi-\pi^{*}$ transitions.

\section{Introduction}

Preparation of nanoscale materials with specific properties is of great fundamental and technological interest. ${ }^{1}$ One of the most challenging problems in this area of research is the production of well-defined chemical systems in a predetermined modular manner. Multinuclear containing compounds exhibiting strong long-range metal-metal coupling represent an important class of metallocomplexes. ${ }^{2}$ These molecules are interesting both from the fundamental (i.e. multiredox processes, magnetic coupling and unpaired electron density migration) and practical (i.e. optoelectronic materials for application in high-speed photonic or redox devices) points of view. ${ }^{3-6}$ An additional interest lies in

aDepartment of Chemistry \& Biochemistry, University of Minnesota Duluth, Duluth, MN 55812, USA. E-mail: vnemykin@d.umn.edu; Fax: +1 218726 7394; Tel: +12187266729

${ }^{b}$ Dipartimento di Scienze e Tecnologie Chimiche, Università di Roma "Tor Vergata", via della ricerca scientifica, 00133 Rome, Italy. E-mail: galloni@scienze.uniroma2.it

"Dipartimento di Chimica, Università degli Studi di Roma "La Sapienza", p.le Aldo Moro 5, 00185 Rome, Italy

${ }^{d} A$. N. Nesmeyanov Institute of Organoelement Compounds, 28 Vavilov Str., 117813 Moscow, Russia

$\dagger$ Electronic supplementary information (ESI) available: ${ }^{1} \mathrm{H}$ and ${ }^{13} \mathrm{C}$ NMR spectra, APCI and APCI MS/MS spectra, ESI spectra, calculated atomic orbital contributions and calculated vertical extension energies. For ESI see DOI: $10.1039 / \mathrm{b} 805156 \mathrm{a}$ the formation of mixed-valence states, an intriguing phenomenon occurring in polynuclear transition-metal complexes, particularly those with ferrocene substituents. ${ }^{5}$ Polyferrocenyl-substituted molecules are among the best candidates for multimetal redox active groups because of their well known metal-metal coupling properties and thermal stability. ${ }^{5}$ The formation of mixed-valence complexes in bisferrocenes was discovered a long time ago and the influence of the different factors on the formation and stability of mixed-valence states has been intensively investigated. ${ }^{7-15}$ The outstanding thermal and chemical stability as well as the possibility of tuning the macrocyclic redox potentials make porphyrins and related compounds outstanding candidates as $\pi$-conjugated skeletons, which are able to connect several redox-active ferrocenyl substituents. ${ }^{16}$ However, in spite of the large progress in understanding the different factors playing a dominant role in the metal-metal coupling process, such as the type of connection, the length of connector, and the orientation of ferrocenyl units, ${ }^{7-15}$ useful molecular devices have not yet been prepared. In most cases, the iron centers should be located at a distance of less than $5.4 \AA$ to achieve effective metal-metal coupling between the ferrocene units in the same molecule, while examples of long range $(\sim 10 \AA)$ metal-metal couplings in polyferrocenyl containing systems are still rare. ${ }^{17-22}$ Meso-ferrocenyl substituted porphyrins have so far received little attention, although they seem very promising in terms of their photochemical properties. ${ }^{21-23}$ For instance, during 
our investigation of the efficient and fast electron transfer from zinc 5,10,15,20-tetraferrocenylporphyrin (ZnTFcP, strong electron donor) to 2-pyridyl-3,4-fulleropyrrolidine (electron acceptor), $\mathrm{ZnTFcP}$ showed interesting photoinduced electron-transfer features. ${ }^{24}$ In 1999, Barrell et al. showed a rare example of the formation of a pure atropisomer of $\alpha, \alpha-5,15$-bis(ferrocenyl)-2,8,12,18tetrabutyl-3,7,13,17-tetramethylporphyrin, which demonstrated long range (>10 $\AA$ ) metal-metal coupling between two ferrocenyl substituents. ${ }^{17}$ The same long range metal-metal coupling and macrocycle metal dependence was later observed for a very similar compound, $\alpha, \alpha-5,15$-bis(ferrocenyl)-2,8,12,18-tetrabutyl3,7,13,17-tetraethylporphyrin. ${ }^{18}$ Both research teams have logically suggested that the probable reason for the observed metal-metal interactions is due to a restricted conformational flexibility of ferrocene groups, because when ferrocenyl groups are conformationally flexible as in 5,15-diferrocenyl-10,20-di- $p$ tolylporphyrin, no metal-metal coupling has been observed. ${ }^{17}$ In accord with this hypothesis, other meso-tetraferrocenyl porphyrin systems, with ferrocenyl units connected to the porphyrin core through aromatic linking groups, were reported to lack the ability to form mixed-valence complexes. ${ }^{25}$

The first 5,10,15,20-tetraferrocenyl porphyrins, MTFcP, were described in $1977^{26}$ but the unacceptably low purity of the reported compounds raises a question about the reported formation of mixed-valence derivatives of MTFcP. The synthesis of pure $\mathrm{H}_{2} \mathrm{TFcP}$ and its transition-metal complexes has not been published until recently and allows us to obtain target compounds in relatively high yields and purity. ${ }^{21,27}$ Several years later, another team of researchers proposed an alternative synthetic route for the preparation of MTFcP compounds and supported Burrell's hypothesis about simultaneous oxidation of all four ferrocene substituents in $\mathrm{MTFcP}$ at the same potential. ${ }^{28}$ The data, however, were in disagreement with our preliminary results on the chemical oxidation of MTFcP complexes ${ }^{22}$ and, considering the unusual photochemical properties of $\mathrm{ZnTFcP}$ in a supramolecular system with fullerene ${ }^{24}$ and the indication of the formation of mixedvalence states in $\mathrm{H}_{2} \mathrm{TFcP}$ and bisferrocenyl-bisphenylporphyrins, ${ }^{21}$ we decided to carefully investigate the redox properties of $\mathrm{H}_{2} \mathrm{TFcP}$ and its transition-metal complexes in order to better understand the interactions between the ferrocene units and the porphyrin core. The results of our investigation are divided into two parts. In the first part, presented here, we discuss the preparation and detailed characterization of the neutral $\mathrm{H}_{2} \mathrm{TFcP}$ and MTFcP $(\mathrm{M}=\mathrm{Co}, \mathrm{Ni}, \mathrm{Cu}$ and $\mathrm{Zn})$ complexes, while the formation, characterization, and stability of chemically or electrochemically generated mixed-valence states in these complexes will be discussed in a second, forthcoming part. While mixed-valence complexes of $\mathrm{H}_{2} \mathrm{TFcP}$ and MTFcP are the primary targets of our studies, the current manuscript provides a necessary experimental and theoretical background for understanding mixed valence properties of the ferrocenyl-containing porphyrins described in our forthcoming paper.

\section{Results and discussion}

\section{Synthesis of $\mathrm{H}_{2}$ TFcP and MTFcP complexes}

The parent $\mathrm{H}_{2} \mathrm{TFcP}$ complex can be prepared using two major synthetic routes already reported in the literature by us or by other research groups. ${ }^{21,22,24,27,28}$ The first approach utilizes Lindsey's procedure for the synthesis of meso-substituted porphyrins, ${ }^{29}$ (i.e. a room temperature reaction between pyrrole and ferrocenecarbaldehyde followed by oxidation with chloranil) with a $40 \%$ yield of target $\mathrm{H}_{2}$ TFcP (Scheme 1). It can also be obtained with an overall $53 \%$ yield using a two-step method ${ }^{28}$ which first requires the preparation of ferrocenyldipyromethane followed by its condensation with ferrocenyl carbaldehyde in acidic conditions (Scheme 1). $\mathrm{H}_{2} \mathrm{TFcP}$ can be readily converted into the MTFcP compounds $(\mathrm{M}=\mathrm{Zn}, \mathrm{Ni}, \mathrm{Co}$, and $\mathrm{Cu})$ by reaction with the respective metal acetates or chlorides in chloroform or DMF. Interestingly, unlike other transition metal MTFcP complexes, $\mathrm{ZnTFcP}$ can also be formed in non-polar or chlorinated solvents even at room temperature, probably because of the better fit between the size of the metal ion and the coordination cavity of $\mathrm{H}_{2} \mathrm{TFcP}$.

It should be noted that all of our attempts to isolate pure $\mathrm{H}_{2} \mathrm{TFcP}$ using a direct condensation of ferrocenecarbaldehyde with pyrrole in acetic acid leads to the isolation of a brown-colored compound, which has spectroscopic characteristics similar to the macrocycle reported in $1977,{ }^{26}$ and is not the pure target complex. This result is not surprising because of the relatively low stability of ferrocene and ferrocene-containing compounds in acidic media. ${ }^{30}$

\section{NMR spectroscopy}

The signals observed for the inner $\mathrm{NH}$ protons in $\mathrm{TFCPH}_{2}$ $(\sim-0.5 \mathrm{ppm})$ reveal a weaker shielding current created by the $\pi$-system inside the porphyrin cavity in comparison to those observed in both cis- $\mathrm{H}_{2} \mathrm{Fc}_{2} \mathrm{Ph}_{2} \mathrm{P}(\sim-1.8 \mathrm{ppm})^{21}$ and $\mathrm{H}_{2} \mathrm{TPP}$ $(\sim-2.2 \mathrm{ppm})$ macrocycles, which is consistent with the degree of non-planarity in these systems predicted by DFT calculations, i.e. $\mathrm{H}_{2} \mathrm{TFcP}>$ cis- $\mathrm{H}_{2} \mathrm{Fc}_{2} \mathrm{Ph}_{2} \mathrm{P}>\mathrm{H}_{2} \mathrm{TPP}$. The disappearance of the NH signals in the ${ }^{1} \mathrm{H}$ NMR spectra of ZnTFcP and NiTFcP clearly confirms the complexation with respective transition-metal ions. In the ${ }^{1} \mathrm{H}$ NMR spectra of diamagnetic $\mathrm{H}_{2} \mathrm{TFcP}$, ZnTFcP and NiTFCP, three clear peaks corresponding to protons at $\alpha$ $\mathrm{Cp}$ (substituted $\mathrm{Cp}$ ring), $\beta-\mathrm{Cp}$ (substituted $\mathrm{Cp}$ ring) and $\mathrm{CpH}$ (unsubstituted $\mathrm{Cp}$ ring) positions were observed in the 5.075.41, 4.66-4.81 and 3.94-4.07 ppm regions, respectively, and are almost independent of solvent polarity $\left(\mathrm{C}_{6} \mathrm{D}_{6}, \mathrm{CDCl}_{3}\right.$ and THF- $\mathrm{d}_{8}$ were tested). Signals of the cyclopentadienyl ligands connected to the porphyrin core are slightly deshielded as compared to those observed for the unsubstituted cyclopentadienyl ligands indicating a small electron-withdrawing effect of the porphyrin macrocycle. $\beta$-Pyrrolic protons also show a single narrow peak between 9.38 and $9.88 \mathrm{ppm}$ (Table 1 and ESI Fig. 1 ) $\dagger$. It is interesting to observe that both the $\alpha$-protons of substituted cyclopentadienyl rings and pyrrolic protons of the free base are shifted upfield in the Ni complex and downfield in the $\mathrm{Zn}$ complex relative to the metal-free compound. This behavior parallels that observed in cisand trans-diferrocenyldi(pentafluorophenyl)porphyrin, ${ }^{19}$ and can be attributed to the higher cationic electronegativity of the $\mathrm{Ni}^{2+}$ ion as compared to that of $\mathrm{Zn}^{2+}$. In support of the hypothesis that electronic density is important in determining shifts of resonances, our systems (with four electron-donating ferrocenyl substituents) resonate downfield with respect to Swarts' system (with two Fc and two electron-withdrawing pentafluorophenyl groups). ${ }^{19}{ }^{13} \mathrm{C}$ NMR spectra of $\mathrm{H}_{2} \mathrm{TFcP}, \mathrm{ZnTFcP}$ and NiTFcP are also similar 

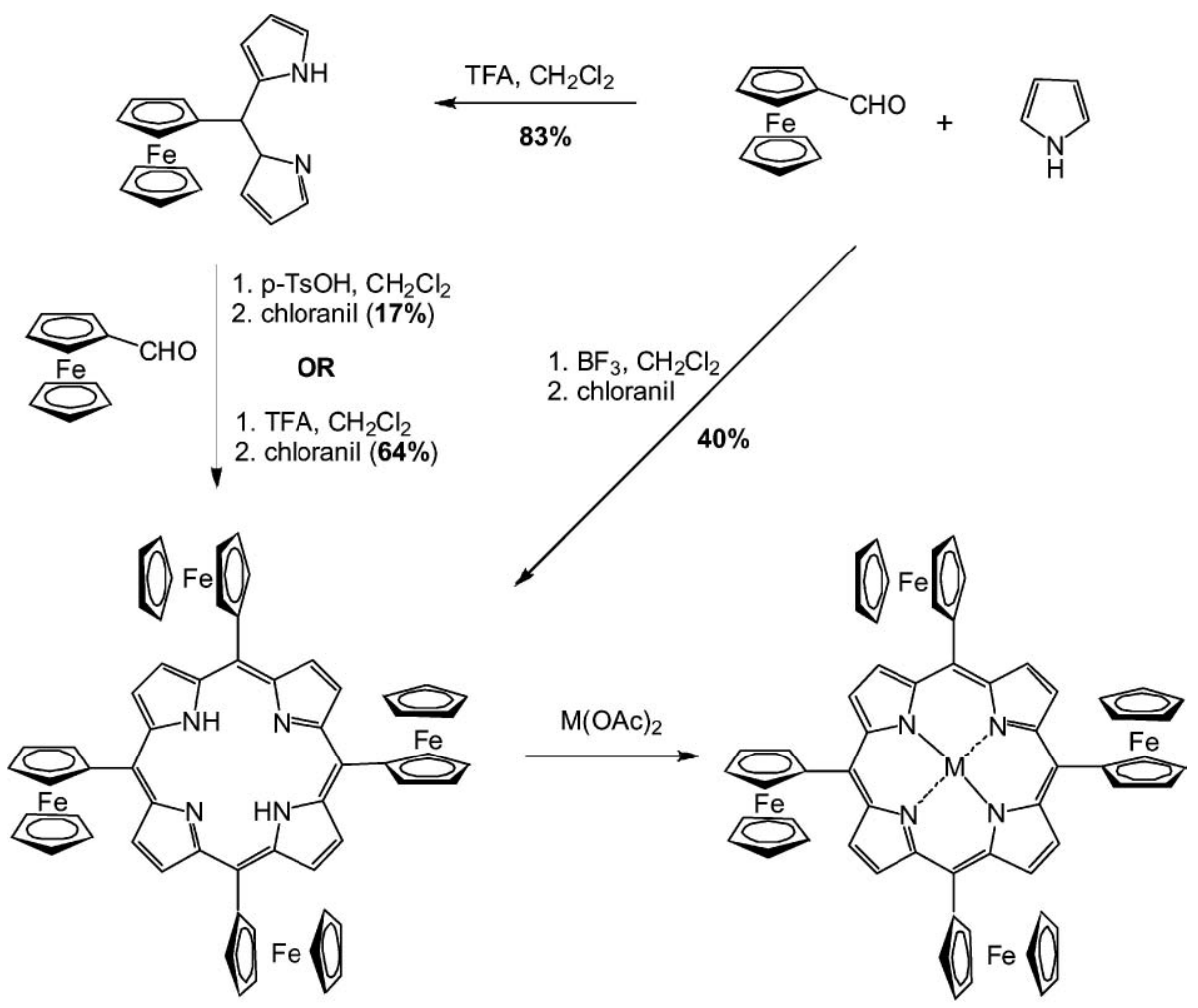

$\mathrm{Co}(\mathrm{OAC})_{2}$ : DMF, $100^{\circ} \mathrm{C}(\mathbf{2 8 \%}) ; \mathrm{CHCl}_{3}$, reflux $(\mathbf{7 9} \%)$

$\mathrm{Ni}(\mathrm{OAC})_{2}$ : DMF, $100^{\circ} \mathrm{C}(47 \%) ; \mathrm{CHCl}_{3}$, reflux $(29 \%)$

$\mathrm{Cu}(\mathrm{OAC})_{2}: \mathrm{DMF}, 100^{\circ} \mathrm{C}(\mathbf{2 8} \%)$

$\mathrm{Zn}(\mathrm{OAc})_{2}: \mathrm{C}_{6} \mathrm{H}_{6}$, reflux $(\mathbf{8 3} \%) ; \mathrm{CHCl}_{3}$, reflux $(57 \%)$

Scheme 1 Preparation of $\mathrm{H}_{2} \mathrm{TFcP}$ and MTFcP complexes.

Table $1{ }^{1} \mathrm{H}$ and ${ }^{13} \mathrm{C}$ NMR data for $\mathrm{H}_{2} \mathrm{TFcP}$, NiTFcP and $\mathrm{ZnTFcP}$ complexes $^{a}$

\begin{tabular}{lccllllll}
\hline & $\alpha$-Pyrr & $\beta$-Pyrr & $\mathrm{C}_{\text {meso }}$ & $\alpha-\mathrm{Cp}$ & $\beta-\mathrm{Cp}$ & $\mathrm{CpH}$ & $\mathrm{Cp}_{\text {ipso }}$ & $\mathrm{NH}$ \\
\hline & & \multicolumn{7}{c}{$\mathrm{N}_{2}$} \\
& & & $\mathrm{H}_{2} \mathrm{TFcP}$ & & & & \\
${ }^{1} \mathrm{H}$ & - & 9.61 & - & 5.32 & 4.75 & 3.97 & - & -0.49 \\
${ }^{13} \mathrm{C}$ & 145.8 & 130.6 & 117.1 & 76.6 & 68.8 & 70.1 & 88.9 & - \\
& & & & NiTFcP & & & & \\
${ }^{1} \mathrm{H}$ & - & 9.38 & - & 5.07 & 4.66 & 3.94 & - & - \\
${ }^{13} \mathrm{C}$ & 145.3 & 132.0 & 115.8 & 75.7 & 69.0 & 70.2 & 87.5 & - \\
& & & & ZnTFcP & & & & \\
${ }^{13} \mathrm{H}$ & & 9.84 & - & 5.37 & 4.80 & 4.07 & - & - \\
${ }^{13} \mathrm{C}$ & 148.9 & 131.6 & 118.2 & 77.1 & 68.7 & 70.3 & 90.1 & -
\end{tabular}

${ }^{a}{ }^{1} \mathrm{H}$ and ${ }^{13} \mathrm{C}$ data were collected in $\mathrm{CDCl}_{3}$ at room temperature. $\mathrm{Ab}$ breviations: $\alpha$-Pyrr ( $\alpha$-pyrrolic hydrogen or carbon), $\beta$-Pyrr ( $\beta$-pyrrolic hydrogen or carbon), $\mathrm{C}_{\text {meso }}$ (meso-carbon), $\alpha$-Cp ( $\alpha$-cyclopentadienyl hydrogen or carbon), $\beta$ - $\mathrm{Cp}$ ( $\beta$-cyclopentadienyl hydrogen or carbon), $\mathrm{CpH}$ (unsubstituted cyclopentadienyl hydrogen or carbon) and $\mathrm{Cp}_{i p s o}(\alpha-i p s o-$ carbon of substituted cyclopentadienyl ligand).

to each other (Table 1). In all cases, pyrrolic $\alpha$-carbons appear as a broad and the most downfield signal, while all other signals appear as sharp peaks. Again, a comparison of the position of ferrocenyl $\mathrm{Cp}_{i p s o}$ and $\alpha-\mathrm{Cp}$ signals with those originated from the unsubstituted $\mathrm{Cp}$ ring is clearly indicative of the weak electronwithdrawing nature of the porphyrin core.

As shown recently, ${ }^{17}$ the rotation of ferrocenyl moieties in the free base $\alpha, \alpha-5,15$-bis(ferrocenyl)-2,8,12,18-tetrabutyl-3,7,13,17-

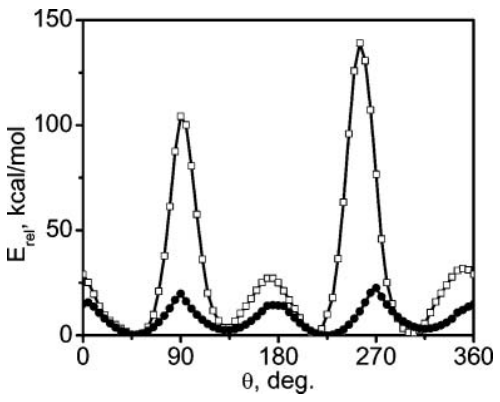

Fig. 1 Rotational barrier profile for ferrocenyl substituents in ZnTFcP complex calculated at PM3 level using 'rigid' (open squares) and 'relaxed' (filled circles) geometries.

tetramethylporphyrin and its nickel complex is strictly limited because of the steric interactions between the ferrocenyl group and alkyl chains attached to the $\beta$-pyrrolic carbon atoms of the porphyrin core. On the other hand, since the substituents are absent at $\beta$-positions in $\mathrm{H}_{2} \mathrm{TFcP}$ and MTFcP complexes, it could be expected that ferrocenyl substituents will undergo free rotation around the $\mathrm{C}_{\text {meso }}-\mathrm{Cp}_{\text {ipso }}$ bond. Indeed, the free rotation of ferrocene substituents around the $\mathrm{C}_{\text {meso }}-\mathrm{Cp}_{\text {ipso }}$ bond at room temperature in $\mathrm{H}_{2} \mathrm{TFcP}$ and $\mathrm{MTFcP}$ complexes was confirmed by variable-temperature NMR experiments. Thus, in the case of $\mathrm{ZnTFcP}$ a sharp room temperature signal of $\beta$-pyrrolic protons, located at $9.84 \mathrm{ppm}$, splits into two broad singlets at $183 \mathrm{~K}$ 
with an integrated ratio of $1: 1$ (ESI Fig. 2). $\dagger$ A standard line broadening analysis of the variable-temperature data ${ }^{31}$ of the $\mathrm{ZnTFcP}$ complex suggests that the rotational barrier of the ferrocenyl substituents in this complex is $\sim 27.3 \mathrm{~kJ} \mathrm{~mol}^{-1}$. As discussed earlier, ${ }^{21}$ variable-temperature NMR experiments on $\mathrm{H}_{2} \mathrm{TFcP}$ in THF reveal two distinct processes (ESI Fig. 2) $\dagger$ attributed to "freezing" of individual NH tautomers ${ }^{32,33}$ and the elimination of rotational freedom of the ferrocene substituents in $\mathrm{H}_{2} \mathrm{TFcP}$ with energies of $\sim 43.4$ and $\sim 26.1 \mathrm{~kJ} \mathrm{~mol}^{-1}$, respectively. ${ }^{34}$ Finally, in the case of the NiTFcP complex, the signals of $\beta$ pyrrolic protons become broader as the temperature decreases, but the coalescence temperature cannot be reached in the solvent temperature window (ESI Fig. 2), $\dagger$ indicating a lower free enthalpy of activation barrier in this case as compared to that observed in $\mathrm{ZnTFcP}$ and $\mathrm{H}_{2} \mathrm{TFcP}$ complexes. The complete analysis of the line broadening in NiTFcP allows us to estimate the free enthalpy of activation in this complex to be $\sim 14.7 \mathrm{~kJ} \mathrm{~mol}^{-1}$.

The variable-temperature data on $\mathrm{H}_{2} \mathrm{TFcP}, \mathrm{ZnTFcP}$ and NiT$\mathrm{FcP}$ complexes are in good agreement with the rotational barrier calculations of ferrocenyl groups at the semi-empirical PM3 level. By using a density functional theory predicted geometry for the $\mathrm{ZnTFcP}$ complex as an example, the calculated minimum rotational barriers were found to be 27.2 and $14.4 \mathrm{~kJ} \mathrm{~mol}^{-1}$ for the "restrained" and "relaxed" geometries, respectively (see Experimental for details) with the energy minima located at nearly 50 and $230^{\circ}$ for the $\mathrm{C}(\alpha-\mathrm{Pyrr})-C_{\text {meso }}(\mathrm{Porph})-\mathrm{Cp}_{\text {ipso }}(\mathrm{Fc})-\alpha \mathrm{Cp}(\mathrm{Fc})$ torsion angle (Fig. 1). Moreover, as shown below, the similarities in the rotational barrier magnitudes for $\mathrm{H}_{2} \mathrm{TFcP}$ and $\mathrm{ZnTFcP}$ complexes along with the significant decrease of this barrier in NiTFcP can be explained on the basis of the difference in the degree of non-planarity of the porphyrin cores in these compounds predicted at DFT level of theory.

\section{UV-vis and MCD spectroscopy}

The electronic and MCD spectra of the $\mathrm{H}_{2} \mathrm{TFcP}$ and MTFcP $(\mathrm{M}=\mathrm{Zn}, \mathrm{Ni}, \mathrm{Co}$ and $\mathrm{Cu})$ complexes are shown in Fig. 2 with band positions and intensities presented in Table 2. In the UVvis spectrum of the $\mathrm{H}_{2} \mathrm{TFcP}$ complex, the Soret band is observed at $434 \mathrm{~nm}\left(10 \mathrm{~nm}\right.$ red-shifted as compared to that in $\left.\mathrm{H}_{2} \mathrm{TPP}\right)$ with a shoulder at $c a 480 \mathrm{~nm}$ with the Q-bands located at 661 $\left(\mathrm{Q}_{1}\right)$ and $726\left(\mathrm{Q}_{2}\right) \mathrm{nm}$. In the MCD spectrum of this compound two s-shaped Faraday pseudo $A$-terms (taking into consideration effective $C_{2}$ symmetry of the complex) are associated with the Soret band and shoulder positions with both signals having their negative component in the low energy region and centered close to the maxima observed in the UV-vis spectrum. In the Q-band region, two Faraday $B$-terms in the MCD spectrum represent $\mathrm{Q}_{1}$ and $\mathrm{Q}_{2}$ bands with the observed maxima of MCD signals close to the absorption maxima in the UV-vis spectrum and the negative $B$-term being located in the low-energy area. The UV-vis spectra of the $\operatorname{MTFcP}(\mathrm{M}=\mathrm{Zn}, \mathrm{Cu}$ and $\mathrm{Ni})$ complexes are similar and consist of a Soret band at $c a 420-435 \mathrm{~nm}$ with a shoulder at $c a 490 \mathrm{~nm}$, and a single transition-metal dependable Q-band observed between 660 and $680 \mathrm{~nm}$, with the prominent shoulder located at slightly higher energy (Fig. 2, Table 2).

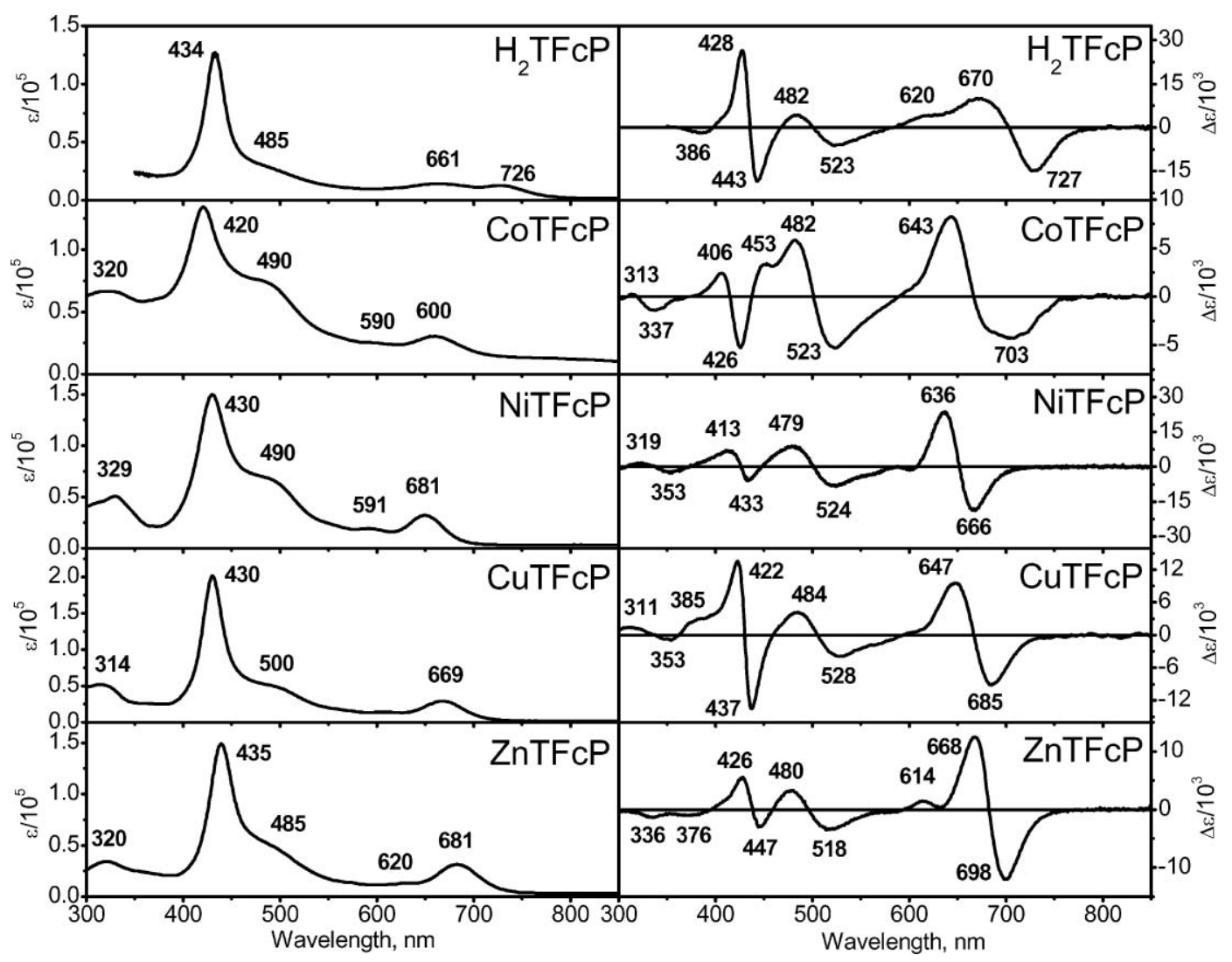

Fig. 2 Room temperature UV-vis (left column) and $\mathrm{MCD}$ (right column) spectra of $\mathrm{H}_{2} \mathrm{TFcP}_{\text {and }} \mathrm{MTFcP}$ complexes $\left(10^{-5} \mathrm{~mol} \mathrm{~L}^{-1}\right)$ in $\mathrm{CHCl}_{3}$. 
Table 2 UV-vis data for $\mathrm{H}_{2} \mathrm{TFcP}$ and MTFcP complexes ${ }^{a}$

$\lambda_{\max } / \mathrm{nm}\left(\varepsilon / \mathrm{mol}^{-1} \mathrm{~cm}^{-1}\right)$

$\mathrm{H}_{2} \mathrm{TFcP}$

$\mathrm{CoTFcP}^{b}$

$\mathrm{NiTFcP}$

$\mathrm{CuTFcP}$

$\mathrm{ZnTFcP}$
434 (120500), $485 \mathrm{sh}, 661$ (17300), $726(15300)$

320 (66500), 420 (134200), $490 \mathrm{sh}, 660$ (30400), $590 \mathrm{sh}, 800 \mathrm{sh}$

$320 \mathrm{sh}, 329$ (50700), 430 (149800), $485 \mathrm{sh}, 591$ (19200), 681 (38800), $800 \mathrm{sh}$

314 (51900), 430 (201700), 500 sh, 600 sh, 669 (29200)

320 (34200), 435 (142800), 485 sh, 620 sh, 681 (31500)

${ }^{a}$ Data were collected in $\mathrm{CHCl}_{3}$ at room temperature with concentrations of $c a 5 \times 10^{-6} ; \mathrm{sh}=$ shoulder; ${ }^{b}$ Recorded in the presence of $\mathrm{NEt}_{3}$ in order to avoid oxidation.

For instance, in the case of $\mathrm{ZnTFcP}$, three strong negative Faraday $A$-terms (indicative of the degenerate excited states in this complex) centered at the absorption maxima of the Soret band, its shoulder, and the Q-band are observed and a similar picture was found in the case of both NiTFcP and CuTFcP complexes (Fig. 2). The overall shape of the MCD spectra of $\mathrm{MTFcP}(\mathrm{M}=\mathrm{Zn}, \mathrm{Cu}$ and $\mathrm{Ni})$ complexes is similar to that observed in closed-shell transition-metal porphyrins having a doubly occupied predominantly porphyrin-based $\mathrm{a}_{1 \mathrm{u}} \mathrm{HOMO}$ and degenerate porphyrin-based e $\mathrm{g}$ LUMO orbitals ( $D_{4 h}$ effective symmetry). ${ }^{35}$ As discussed below, however, DFT calculations predict numerous predominantly ferrocenyl-based orbitals in $\mathrm{H}_{2} \mathrm{TFcP}$ and $\mathrm{MTFcP}$ complexes lying between the above mentioned porphyrin-based orbitals. Such an electronic structure can give rise to a large number of metal-to-ligand charge-transfer bands in the UV-vis and MCD spectra of $\mathrm{H}_{2} \mathrm{TFcP}$ and $\mathrm{MTFcP}$ complexes, which is discussed on the basis of TDDFT calculations presented below. The most striking difference between the MCD spectra of $\mathrm{H}_{2} \mathrm{TFcP}$ and $\mathrm{MTF}$ P complexes is the relative intensity of MCD signals in the Soret to Q-band regions. For instance, in the case of the $\mathrm{H}_{2} \mathrm{TFcP}$ complex, the pseudo Faraday $A$-term corresponding to the Soret band is $\sim 1.5$ times more intense as compared to the Q-band region Faraday $B$-terms, while in the case of MTFcP complexes, the situation is different (Fig. 2). In the case of CoTFcP, the electronic spectrum suggests the possibility that both $\mathrm{Co}^{2+}$ and $\mathrm{Co}^{3+}$ centers are present in solution. Indeed, upon addition of a reducing agent $\left(\mathrm{NEt}_{3}\right.$ or $\left.\mathrm{NaBH}_{4}\right)$, the spectrum became similar to that of MTFcP $(\mathrm{M}=\mathrm{Ni}, \mathrm{Cu}$ and $\mathrm{Zn})$. Interestingly, extinction coefficients of the $\mathrm{H}_{2} \mathrm{TFcP}$ and MTFcP complexes are quite different for the same concentrations in the different solvents. Our initial studies are clearly indicative of the aggregation of $\mathrm{H}_{2} \mathrm{TFcP}$ and MTFcP, which will be discussed in a separate paper.

\section{XPS results}

$\mathrm{H}_{2}$ TFcP has two symmetry-distinct and electronically inequivalent nitrogen atoms, which are denoted as $\mathrm{N}_{\mathrm{A}}$ and $\mathrm{N}_{\mathrm{B}}$ in Table 3 and Fig. 3. They are related to the unprotonated and protonated porphyrin-ring nitrogens $(=\mathrm{N}-$ and $-\mathrm{NH}-$ ), respectively, as previously reported in the literature. ${ }^{36}$ In a previous publication, ${ }^{37}$ we proposed to take the $\mathrm{BE}$ separation, $\triangle \mathrm{BE}$, of each $\mathrm{N} 1 \mathrm{~s}$ peak component from the $\mathrm{C} 1 \mathrm{~s}$ peak of the porphyrin-ring carbon, as a reference value for accurately assigning $\mathrm{N}_{\mathrm{A}}$ and $\mathrm{N}_{\mathrm{B}}$ in porphyrinbased systems. Based on a review analysis of the $\mathrm{BE}$ data on various porphyrins, $\mathrm{N}_{\mathrm{A}}$ and $\mathrm{N}_{\mathrm{B}}$ always present $\triangle \mathrm{BE}$ values of 113 and $115 \mathrm{eV}$, respectively, with a small associated uncertainty. The $\mathrm{N}_{\mathrm{A}, \mathrm{B}}$ components converge into a single $\mathrm{N}_{\mathrm{C}}$ peak representing the
Table 3 Atomic ratios and binding energies (eV) of $\mathrm{H}_{2} \mathrm{TFcP}$, and $\mathrm{MTFcP}$ complexes obtained in XPS experiments

\begin{tabular}{|c|c|c|c|c|c|}
\hline Complex & $\mathrm{H}_{2} \mathrm{TFcP}$ & CoTFcP & NiTFcP & CuTFcP & $\mathrm{ZnTFcP}$ \\
\hline \multicolumn{6}{|l|}{ Atomic ratios } \\
\hline $\mathrm{N}_{\mathrm{B}} / \mathrm{N}_{\mathrm{A}}$ & 1.3 & - & - & - & - \\
\hline $\mathrm{N} / \mathrm{Fe}^{a}$ & 1.0 & 1.4 & 1.1 & 1.1 & 1.0 \\
\hline $\mathrm{N} / \mathrm{M}^{b}$ & - & 5.8 & 4.2 & 4.2 & 3.6 \\
\hline $\mathrm{Fe} / \mathrm{M}^{b}$ & - & 4.2 & 3.8 & 3.7 & 3.6 \\
\hline \multicolumn{6}{|c|}{ Binding energies/eV } \\
\hline $\mathrm{N}_{\mathrm{A}}$ & 398.1 & - & - & - & - \\
\hline $\mathrm{N}_{\mathrm{B}}$ & 400.1 & - & - & - & - \\
\hline $\mathrm{N}_{\mathrm{C}}$ & - & 398.8 & 398.8 & 398.9 & 398.5 \\
\hline \multicolumn{6}{|l|}{$\Delta \mathrm{BE} \mathrm{N}(1 \mathrm{~s})-\mathrm{C}(1 \mathrm{~s})$} \\
\hline $\mathrm{N}_{\mathrm{A}}$ & 113.1 & - & - & - & - \\
\hline $\mathrm{N}_{\mathrm{B}}$ & 115.1 & - & - & - & - \\
\hline $\mathrm{N}_{\mathrm{C}}$ & - & 113.8 & 113.8 & 113.9 & 113.5 \\
\hline $\mathrm{Fe}(\mathrm{II}) 2 \mathrm{p} 3 / 2$ & 708.2 & 707.7 & 707.9 & 708.3 & 708.3 \\
\hline $\mathrm{M} 2 \mathrm{p} 3 / 2$ & - & 781.4 & 855.3 & 934.2 & 1021.8 \\
\hline
\end{tabular}

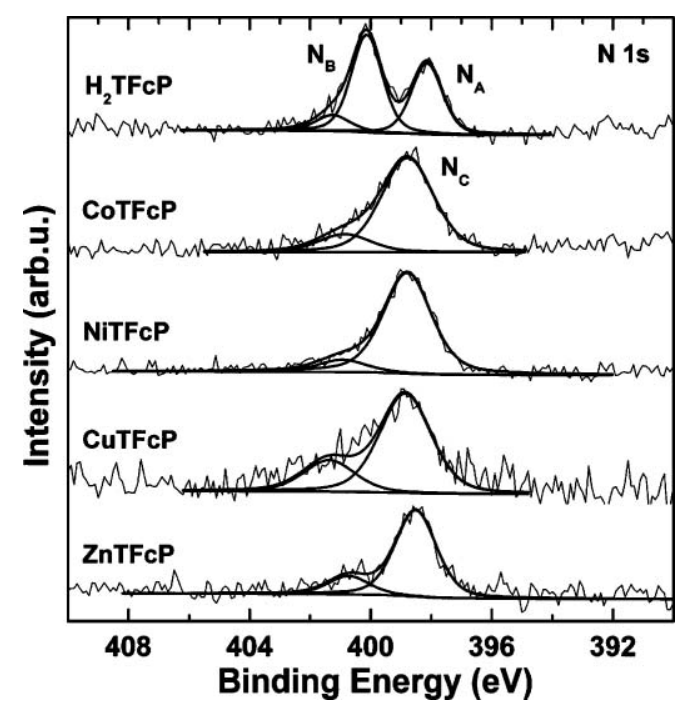

Fig. 3 Experimental and theoretically reconstructed N 1s XPS spectra for $\mathrm{H}_{2} \mathrm{TFcP}$ and MTFcP.

four equivalent metal-ligated nitrogens upon complexation by a metal ion, and the energy separation of $\mathrm{N}_{\mathrm{C}}$ from $\mathrm{C} 1 \mathrm{~s}$ becomes 114 $\pm 0.3 \mathrm{eV}$. This approach overcomes the known problem of a correct $\mathrm{N} 1 \mathrm{~s}$ assignment in the presence of charging effects, which plague XPS data from non-conductors. ${ }^{38}$ The $\mathrm{N} 1 \mathrm{~s}$ peak components for the free bases and their corresponding porphyrinates investigated here strictly follow the energy separations listed above (Table 3) showing the formation of each porphyrinate as a pure species. 
The investigated porphyrinates also show an additional $\mathrm{N}$ 1s peak component much less intense than the dominant one, falling in the BE range of 401-402 eV, where satellite peaks are found in porphyrins. ${ }^{38,39}$ These satellites have been generally attributed to the configuration interaction between primary $\mathrm{N} 1 \mathrm{~s}$ photoelectrons and valence molecular orbitals in analogy to what is found in other extensively delocalized aromatic systems.

$\mathrm{Fe}(\mathrm{II})$ was the largely dominant species in $\mathrm{Fe} 2 \mathrm{p}$ peaks, although a small intensity in the region of $\mathrm{Fe}(\mathrm{III})(711-712 \mathrm{eV})$ was always found, likely due to some surface oxidation of the sample. (Fig. 4). In general, BE and FWHM values resulting from the curve fitting of $\mathrm{Fe} 2 \mathrm{p}$ peak envelopes reproduce literature findings for ferrocene. ${ }^{40}$ The narrow FWHM of the Fe(II) feature, $\sim 1.5 \mathrm{eV}$, favours an assignment to a well-defined molecular moiety, supporting the chemical equivalence of the four peripheral ferrocenyl groups.

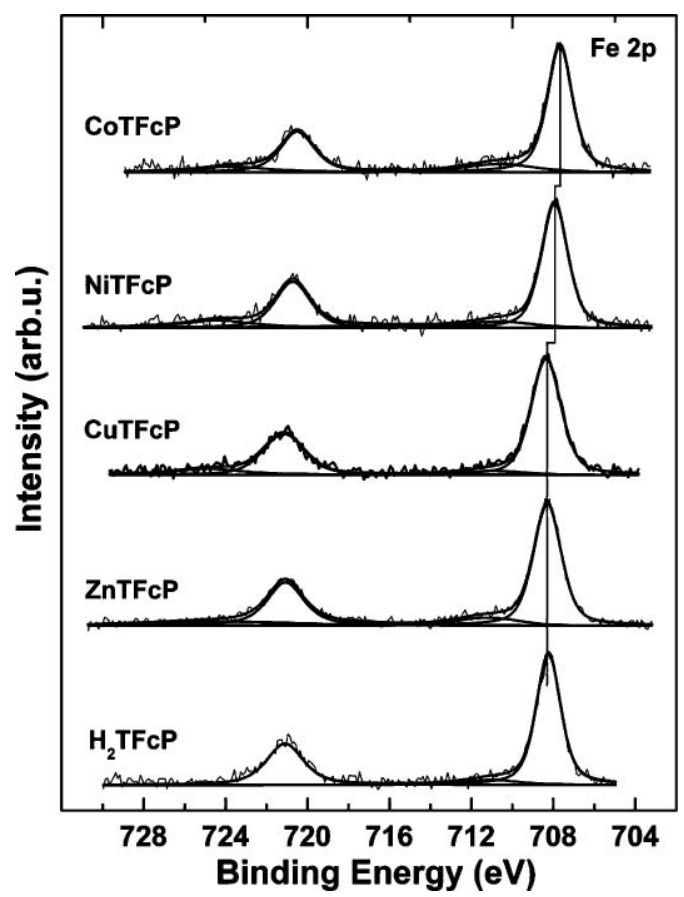

Fig. 4 Experimental and theoretically reconstructed Fe 2p XPS spectra for $\mathrm{H}_{2} \mathrm{TFcP}$ and MTFcP complexes. A minor $\mathrm{Fe}(0)$ component has been numerically subtracted from the spectrum of $\mathrm{CuTFcP}$ for clarity.

Characteristic signals for M(II) species were detected for MTFcP complexes $\left(\mathrm{M}=\mathrm{Co}, \mathrm{Ni}, \mathrm{Cu}\right.$ and $\mathrm{Zn}$, Fig. 5). ${ }^{36} \mathrm{XPS}$ atomic ratios of nitrogen atoms to the central metal or iron, and of iron to the coordinated metal ions reflect the corresponding expected stoichiometries, within experimental uncertainty.

The different $\mathrm{BE}$ values found for $\mathrm{Fe} 2 \mathrm{p}$ hint at an electronic coupling between the ferrocenes and the porphyrin core, modulated by the central metal ion (Table 3). The negative Fe $2 \mathrm{p} \mathrm{BE}$ shift in CoTFcP and NiTFcP suggests an electron enrichment at the Fe sites in the compounds, while no net effect can be traced in both $\mathrm{Cu}$ and $\mathrm{Zn}$ porphyrinates. This is consistent with the Mössbauer results for the $\mathrm{ZnTFcP}$ reported in the next section. In the case of CoTFcP, the Co $2 p$ ionization region is complicated by the presence of an Auger peak (see the Experimental section for details). This hampers a detailed analysis of the peak components

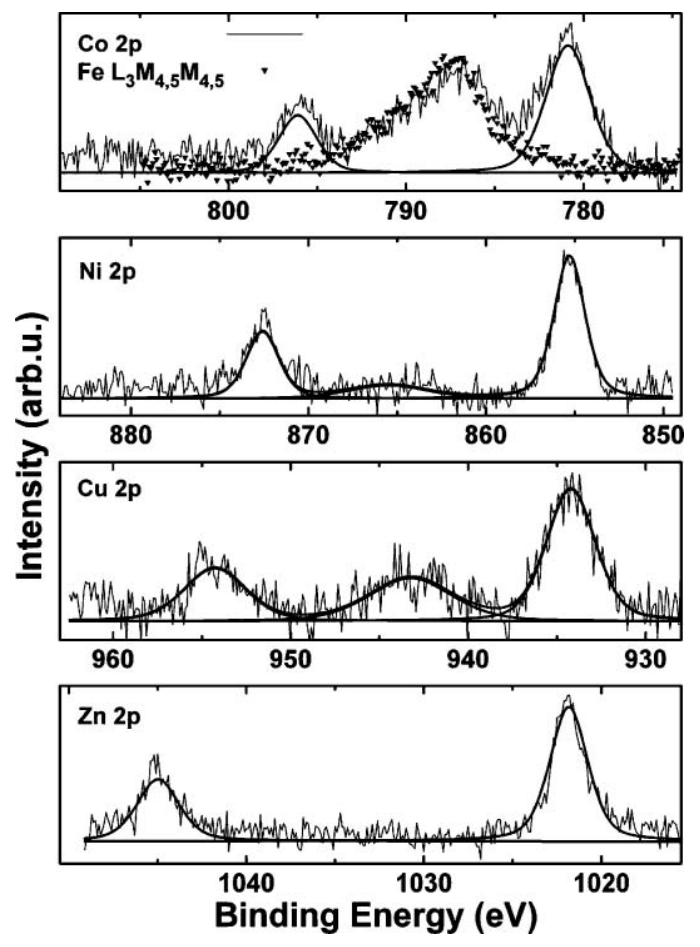

Fig. 5 Experimental and theoretically reconstructed XPS spectra of the $2 \mathrm{p}$ photoionization region of metal ions in MTFcP complexes. The $\mathrm{Fe}$ L3M4,5M4,5 Auger line largely contributes to the Co $2 \mathrm{p}$ photoelectron region in $\mathrm{CoTFcP}$ (full line), as shown by the overlapped spectrum reported for $\mathrm{H}_{2} \mathrm{TFcP}$ (triangles).

and alters its quantitation, while revealing $\mathrm{Co}$ (II) as the prevailing species.

\section{Mössbauer spectroscopy}

The Mössbauer spectra were recorded for both the $\mathrm{H}_{2} \mathrm{TFcP}$ and ZnTFcP complexes and are shown in Fig. 6 with the spectral parameters presented in Table 4 . The isomer shifts and quadrupole splittings observed for the $\mathrm{H}_{2} \mathrm{TFcP}$ and $\mathrm{ZnTFcP}$ complexes are close to those in parent ferrocene (room-temperature isomer shift of $0.44 \mathrm{~mm} \mathrm{~s}^{-1}$, and quadrupole splitting of $\left.2.37 \mathrm{~mm} \mathrm{~s}^{-1}\right)^{46}$ and clearly indicate the presence of only one type of low-spin, ferrous centers in both tested starting compounds. In addition, the data indicate the negligible influence of the porphyrin core on the electronic structure of the iron centers in both the $\mathrm{H}_{2} \mathrm{TFcP}$ and

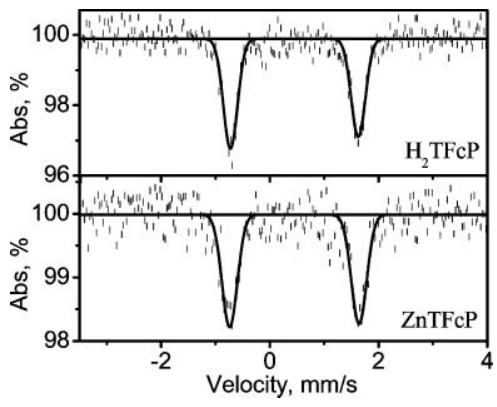

Fig. 6 Room-temperature Mössbauer spectra of $\mathrm{H}_{2} \mathrm{TFcP}$ and $\mathrm{ZnTFcP}$ complexes. 
Table 4 Experimental and DFT-predicted Mössbauer quadrupole splittings in $\mathrm{H}_{2} \mathrm{TFcP}$ and MTFcP complexes

\begin{tabular}{|c|c|c|c|c|c|}
\hline & \multicolumn{3}{|c|}{ EFG elements/au } & \multicolumn{2}{|c|}{$\Delta E_{\mathrm{q}} / \mathrm{mm} \mathrm{s}^{-1}$} \\
\hline & $V_{\mathrm{xx}}$ & $V_{\mathrm{yy}}$ & $V_{\mathrm{zz}}$ & Calcd & $\operatorname{Expt}^{c}$ \\
\hline \multicolumn{6}{|l|}{$\mathrm{H}_{2} \mathrm{TFcP}$} \\
\hline $\mathrm{Fe}_{1}^{a}$ & 0.661 & 0.801 & -1.462 & 2.372 & 2.35 \\
\hline $\begin{array}{l}\mathrm{Fe}_{2}{ }^{a} \\
\mathrm{CoTFcP}\end{array}$ & 0.663 & 0.795 & -1.458 & 2.365 & 2.35 \\
\hline $\begin{array}{l}\mathrm{Fe}^{b} \\
\mathrm{NiTFcP}\end{array}$ & 0.739 & 0.844 & -1.583 & 2.566 & - \\
\hline $\begin{array}{l}\mathrm{Fe}^{b} \\
\mathrm{CuTFcP}\end{array}$ & 0.724 & 0.816 & -1.540 & 2.495 & - \\
\hline $\begin{array}{l}\mathrm{Fe}^{b} \\
\mathrm{ZnTFcP}\end{array}$ & 0.729 & 0.851 & -1.580 & 2.562 & - \\
\hline $\mathrm{Fe}^{b}$ & 0.723 & 0.850 & -1.573 & 2.550 & 2.38 \\
\hline
\end{tabular}

${ }^{a} \mathrm{Fe}_{1}$ and $\mathrm{Fe}_{2}$ represents two non-equivalent iron centers in $\mathrm{H}_{2} \mathrm{TFcP} .{ }^{b}$ All four iron centers in $\mathrm{MTFcP}$ are equivalent, both $\mathrm{H}_{2} \mathrm{TFcP}$ and $\mathrm{ZnTFcP}$ have the same $\left(0.45 \mathrm{~mm} \mathrm{~s}^{-1}\right)$ isomer shift at room temperature. ${ }^{c}$ Room temperature.

$\mathrm{ZnTFcP}$ complexes and provide further evidence on the purity of neutral complexes.

\section{Mass spectroscopy}

APCI mass spectra of $\mathrm{H}_{2}$ TFcP and MTFcP complexes are presented in the ESI Fig. 3. $\dagger$ In the case of $\mathrm{H}_{2} \mathrm{TFcP}, \mathrm{NiTFcP}$ and $\mathrm{CuTFcP}$ they almost exclusively consist of protonated molecular ions. In addition to this peak, in the APCI spectrum of ZnTFcP complex, an intense peak of $[\mathrm{M}+\mathrm{THF}+\mathrm{H}]^{+}$is also present, which reflects the well-known tendency of zinc porphyrinates to coordinate a single axial ligand. ${ }^{41}$ The APCI spectrum of the CoTFcP complex almost exclusively consists of a peak with $\mathrm{m} / \mathrm{z}=$ 1136, which can be attributed to the $\left[\mathrm{M}+\mathrm{O}_{2}+\mathrm{H}\right]^{+}$ion. Although such oxygen adducts of cobalt(II) porphyrins, related macrocycles, and other transition metal based oxygen-transfer reagents are well-known, ${ }^{42}$ the high-resolution ESI spectrum of the CoTFcP complex was collected in order to confirm this tentative assignment (ESI Fig. 3). $\dagger$ In the case of the ESI method, the spectrum almost exclusively consists of $[\mathrm{M}+\mathrm{H}]^{+},[\mathrm{M}+\mathrm{O}+\mathrm{H}]^{+}$, and $\left[\mathrm{M}+\mathrm{O}_{2}+\right.$ $\mathrm{H}]^{+}$ions confirming the high affinity of CoTFcP for oxygen under APCI and ESI conditions.

As it has been shown recently, collision-induced dissociation can provide valuable information on the stability of metal-ligand bonds in inorganic and organometallic compounds, ${ }^{43}$ and thus, $\mathrm{H}_{2}$ TFcP and MTFcP complexes were investigated using the APCI MS/MS approach. The data presented in the ESI Fig. $3 \dagger$ reveal similar collision-induced fragmentation patterns for the $\mathrm{H}_{2} \mathrm{TFcP}$ and $\mathrm{MTFcP}(\mathrm{M}=\mathrm{Zn}, \mathrm{Cu}$ and $\mathrm{Ni})$ complexes. For instance, in the case of $\mathrm{ZnTFcP}$, the initial molecular ion sequentially eliminates a cyclopentadienyl ligand(s) and the whole ferrocene substituent(s) with the formation of a $[\mathrm{M}-\mathrm{Cp}-\mathrm{Fe}]^{+},[\mathrm{M}-\mathrm{Fc}]^{+},[\mathrm{M}-\mathrm{Fc}-\mathrm{Cp}]^{+},[\mathrm{M}-$ $\mathrm{Fc}-2 \mathrm{Cp}]^{+},[\mathrm{M}-2 \mathrm{Fc}-\mathrm{Cp}]^{+}$, and $[\mathrm{M}-2 \mathrm{Fc}-2 \mathrm{Cp}]^{+}$ions as the major fragments (ESI Fig. 3). $\uparrow$ Similar dissociation of cyclopentadienyl and ferrocenyl fragments from the parent ion was also observed in the case of the $\mathrm{H}_{2} \mathrm{TFcP}, \mathrm{NiTFcP}$ and $\mathrm{CuTFcP}$ complexes, while the porphyrin core remains intact in excellent agreement with previously discussed fragmentation patterns observed for porphyrin compounds. ${ }^{44}$ The fragmentation of the CoTFcP complex under APCI MS/MS conditions, however, is completely different. Although the initial oxygen adduct of CoTFcP $\left(\mathrm{O}_{2} \mathrm{CoTFcP}+\right.$ $\mathrm{H})$ eliminates a $\mathrm{Cp}$ ligand with the formation of a $[\mathrm{M}-\mathrm{Cp}]^{+}$ ion, the two major fragment ions observed at $m / z=923$ and 906 originate from the elimination of $\mathrm{Fc}-\mathrm{C}-\mathrm{O}$ and $\mathrm{Fc}-\mathrm{C}-\mathrm{OOH}$ fragments (ESI Fig. 3) $\uparrow$ In both cases, the extra carbon atom probably originates from the meso-position of the porphyrin core, which is unexpected taking into consideration the high stability of the porphyrin core. Such an unusual behavior can be explained by the presence of a coordinated molecule of oxygen, which can oxygenate the porphyrin core at either the $\alpha$-pyrrolic or meso-carbon positions in accord with that suggested for several transition-metal phthalocyanines. ${ }^{45}$

\section{Electronic structure and conformations of $\mathrm{H}_{2} \mathrm{TFcP}$ and MTFcP complexes}

The molecular geometries and electronic structures of $\mathrm{H}_{2} \mathrm{TFcP}$ and MTFcP were calculated at the DFT level. Optimized molecular structures are presented in Fig. 7, while the most important bond distances and angles are listed in Table 5. The calculated parameters reflect the expected $C_{2}\left(\mathrm{H}_{2} \mathrm{TFcP}\right)$ or $S_{4}$ (MTFcP) effective molecular symmetries in the complexes under consideration. In all cases, the global minima require formation of $\alpha, \beta, \alpha, \beta$ - atropisomers. As expected, the ferrocene substituents are not co-planar with the porphyrin core with $\mathrm{C}(\alpha-\mathrm{Pyrr})-$ $\mathrm{C}$ (meso)- $\mathrm{C}($ ipso $)-\mathrm{C}(\alpha-\mathrm{Cp})$ torsion angles varying between $40.9-$ $47.9^{\circ}$ (Table 5). The optimized porphyrin core for all complexes under consideration adopts a ruffled conformation, with NiTFcP and CoTFcP complexes showing significantly larger deviations from the $\mathrm{N}_{4}$ plane as compared to that found in $\mathrm{H}_{2} \mathrm{TFcP}, \mathrm{ZnTFcP}$ and CuTFcP compounds (Fig. 7). It is possible to suggest that the larger deviation from planarity in NiTFcP is responsible for the experimentally observed lower rotational barrier of ferrocenyl substituents in this complex as compared to the more planar ZnTFcP and $\mathrm{H}_{2}$ TFcP compounds. Indeed, based on simple semiempirical calculations (not shown) the ferrocenyl substituent is too large to freely rotate around the $\mathrm{C}$ (meso)- $\mathrm{C}$ (ipso) bond if the porphyrin core is planar. Deviation of the porphyrin core from planarity allows such a rotation, and the larger the deviation, the more freely the ferrocenyl substituent can be rotated. Although it could be helpful to directly compare the degree of non-planarity predicted at the DFT level with experimentally observed data for $\mathrm{H}_{2}$ TFcP and MTFcP, all our attempts to obtain suitable crystals for X-ray analysis have failed.

The molecular orbital diagrams for the predominantly transition-metal based orbitals of $\mathrm{H}_{2} \mathrm{TFcP}$ and MTFcP complexes are presented in Fig. 8, while selected molecular orbitals and their compositions are depicted in Fig. 9 and 10 with their relative energies presented in the ESI Table $1 . \dagger$

In all the diamagnetic compounds, the HOMO predominantly consists of cyclopentadienyl ligand $\pi$ orbitals coupled with the iron $\mathrm{d}_{x y}$ atomic orbital. This orbital is energetically separated from the series of lower-energy, almost pure ferrocenyl-based molecular orbitals (Fig. 10 and ESI Table 1). $\dagger$ As expected, iron $\mathrm{d}_{x y}, \mathrm{~d}_{x^{2}-y^{2}}$, and $\mathrm{d}_{z^{2}}$ atomic orbitals contribute to the formation of these ferrocene-based MOs.

Again, in the diamagnetic compounds, the LUMO and LUMO +1 are degenerate $(\mathrm{ZnTFCP}$ and NiTFcP) or almost 

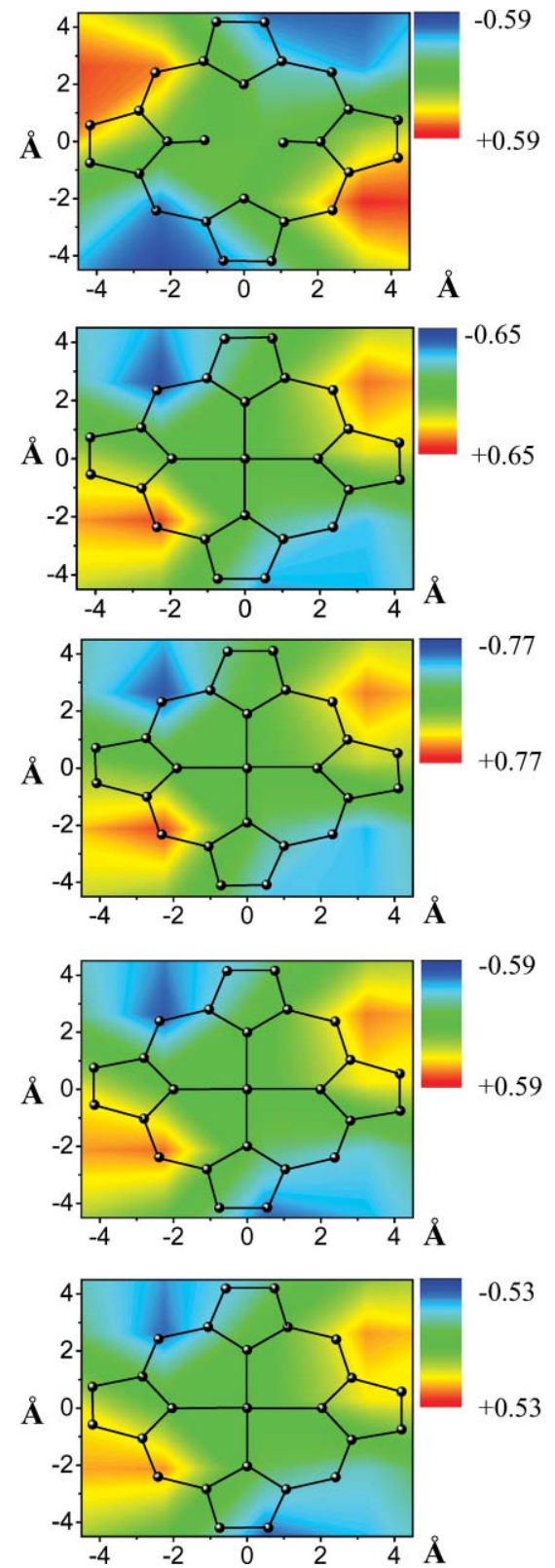

$\mathrm{H}_{2} \mathrm{TFcP}$

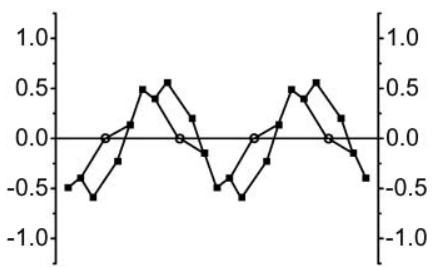

CoTFcP

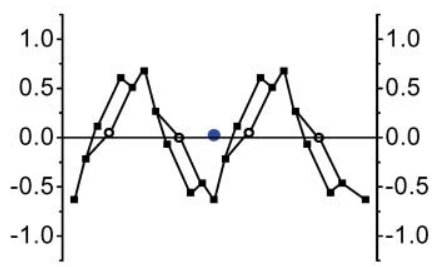

NiTFcP

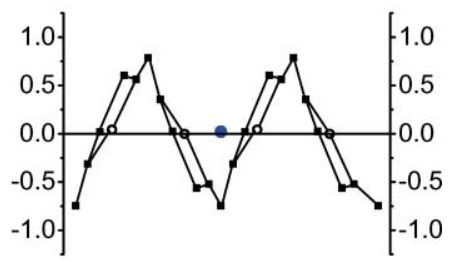

CuTFcP

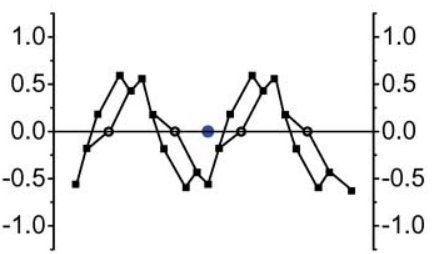

ZnTFcP

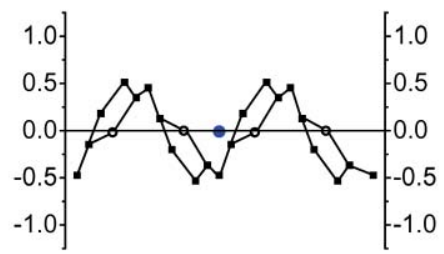

Fig. 7 2D counterplot analyses and linear display deviations from planarity calculated for $\mathrm{H}_{2} \mathrm{TFcP}$ and MTFcP complexes at DFT level (only the porphyrin core deviations are shown).

degenerate $\left(\mathrm{H}_{2} \mathrm{TFcP}\right)$ and the predominantly porphyrin-based $\pi^{*}$ orbitals are energetically well-separated from the LUMO + 2 and higher energy unoccupied MOs, which have significant contributions from iron $\mathrm{d}_{x z}$ and $\mathrm{d}_{y z}$ atomic orbitals (Fig. 10 and ESI Table 1$). \dagger$ In the case of the paramagnetic complexes (CoTFcP and $\mathrm{CuTFcP}$ ), however, both the HOMO ( $\alpha$-set) and LUMO ( $\beta$ set) are central-metal based orbitals in excellent agreement with the experimental data.

Further validity of the electronic structure of $\mathrm{H}_{2} \mathrm{TFcP}$ and MTFcP was supported by the calculation of the Mössbauer quadrupole splittings in these complexes (Table 4). Indeed, the calculated quadrupole splitting and asymmetry parameter in $\mathrm{H}_{2} \mathrm{TFcP}$ and $\mathrm{ZnTFCP}$ are in excellent agreement with the experimental data, while those calculated for other MTFcP compounds are in a range of values that are expected for ferrocenyl-containing porphyrins. ${ }^{46,47}$

As it was mentioned in the previous sections, the UV-vis spectra of the $\mathrm{H}_{2} \mathrm{TFcP}$ and MTFcP complexes look similar to those observed in the respective tetraaryl-porphyrins. The calculated electronic structure of the $\mathrm{H}_{2} \mathrm{TFcP}$ and MTFcP compounds, on the other hand, reveals multiple predominantly ferrocenyl-based orbitals located between occupied and unoccupied predominantly porphyrin-based $\pi$-orbitals (Fig. 10). The presence of these orbitals can, in principle, give rise to the numerous predominantly metal-to-ligand charge-transfer transitions (originate from HOMO-HOMO $-n$ to LUMO) in addition to the expected traditional porphyrin-based $\pi-\pi^{*}$ excitations. Thus, in order to gain additional insight into the nature of the absorption bands in the 
Table 5 Most important distances and torsion angles for metal-free and metal containing tetraferrocenyl porphyrins calculated using density functional theory

\begin{tabular}{|c|c|c|c|c|c|}
\hline Distances/Å & $\mathrm{H}_{2} \mathrm{TFcP}$ & CoTFcP & NiTFcP & $\mathrm{CuTFcP}$ & $\mathrm{ZnTFcP}$ \\
\hline $\mathrm{Fe}_{1}-\mathrm{Fe}_{2}$ & 9.763 & 9.889 & 9.966 & 9.844 & 9.801 \\
\hline $\mathrm{Fe}_{1}-\mathrm{Fe}_{3}$ & 12.043 & 11.477 & 11.359 & 11.703 & 11.941 \\
\hline $\mathrm{Fe}_{1}-\mathrm{Fe}_{4}$ & 9.828 & 9.889 & 9.966 & 9.844 & 9.801 \\
\hline $\mathrm{Fe}_{2}-\mathrm{Fe}_{3}$ & 9.828 & 9.889 & 9.966 & 9.844 & 9.801 \\
\hline $\mathrm{Fe}_{2}-\mathrm{Fe}_{4}$ & 11.981 & 11.477 & 11.359 & 11.703 & 11.941 \\
\hline $\mathrm{Fe}_{3}-\mathrm{Fe}_{4}$ & 9.763 & 9.889 & 9.966 & 9.844 & 9.801 \\
\hline $\mathrm{M}-\mathrm{N}$ & - & 1.953 & 1.904 & 1.996 & 2.039 \\
\hline
\end{tabular}

$\alpha-$ Pyrr $-\mathrm{C}_{\text {meso }}-\mathrm{C}_{i p s o}-\alpha-\mathrm{C}$ Torsion Angles $/{ }^{\circ b}$

\begin{tabular}{lrrrrr}
\hline $\mathrm{Fc}_{1}{ }^{c}$ & 47.9 & 44.3 & 47.9 & 42.0 & 40.9 \\
$\mathrm{Fc}_{2}{ }^{c}$ & -45.7 & -45.6 & -45.7 & -43.6 & -43.9 \\
$\mathrm{Fc}_{3}{ }^{c}$ & 47.9 & 44.3 & 47.9 & 42.0 & 40.9 \\
$\mathrm{Fc}_{4}{ }^{c}$ & -45.7 & -45.6 & -45.7 & -43.6 & -43.9
\end{tabular}

${ }^{a} \mathrm{Fe}_{1}-\mathrm{Fe}_{4}$ represents four iron centers in $\mathrm{H}_{2} \mathrm{TFcP}$ and MTFcP complexes. ${ }^{b}$ Abbreviations are given in Table $1 .{ }^{c} \mathrm{Fc}_{1}-\mathrm{Fc}_{4}$ represents the ferrocenyl ligands with $\mathrm{Fe}_{1}-\mathrm{Fe}_{4}$ centers.

UV-vis and MCD spectra of $\mathrm{H}_{2}$ TFcP and MTFcP complexes, the vertical excitation energies of the $\mathrm{H}_{2} \mathrm{TFcP}$ complex were calculated using a time-dependent DFT (TDDFT) approach. This method has proven to provide a good agreement between theoretical and experimental vertical excitation energies in transition-metal

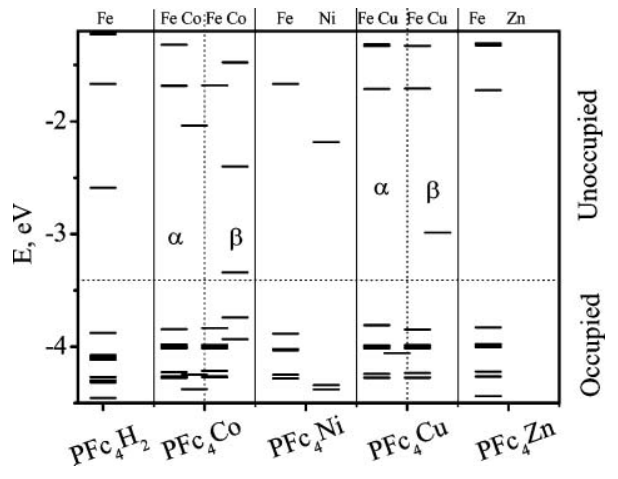

Fig. 8 Molecular orbital diagram for the predominantly 3d-based orbitals localized at the iron ferrocenyl or central transition-metal centers in $\mathrm{H}_{2} \mathrm{TFcP}$ and MTFcP complexes.

complexes $^{48}$ as well as porphyrins and related macrocycles. ${ }^{49}$ The calculated vertical excitation energies of the $\mathrm{H}_{2} \mathrm{TFcP}$ complex are presented in Fig. 11 and reflect a very good agreement between theory and experiment although the TDDFT energies are systematically underestimated (ESI Table 2). $\dagger$ In excellent agreement with the electronic structure calculations, almost all bands with nonzero intensities are predominantly metal-to-ligand charge-transfer (MLCT) in nature. More interestingly, although predominantly porphyrin-based $\pi$-orbitals $254-257$ significantly contribute to the Soret band region excitations, a strong configurational interaction with higher energy occupied, predominantly ferrocene-centered

Predominantly central-metal based orbitals:

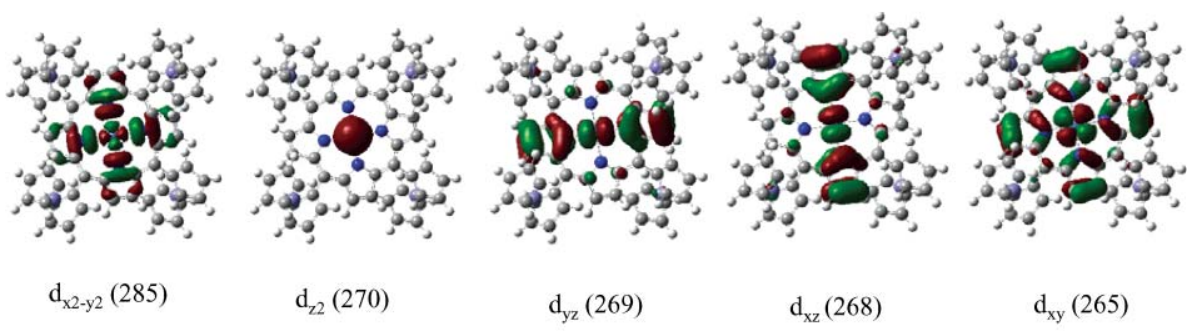

Selected predominantly ferrocene-based orbitals:

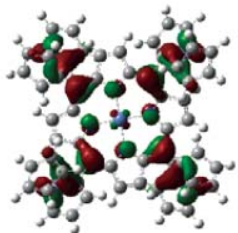

HOMO (282)

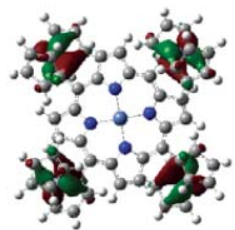

HOMO-1 (281)

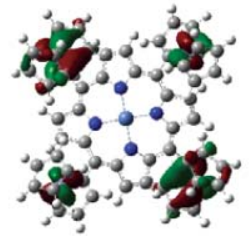

HOMO-2 (280)

Selected predominantly porphyrin-based orbitals:

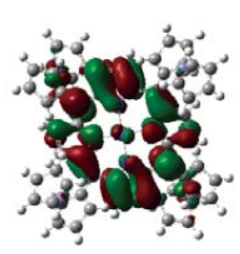

LUMO +1 (284)

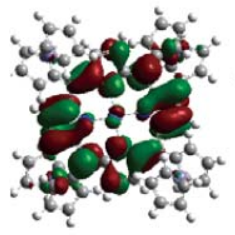

LUMO (283)

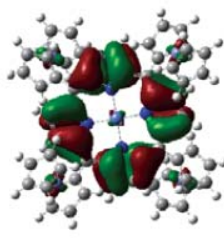

(267)

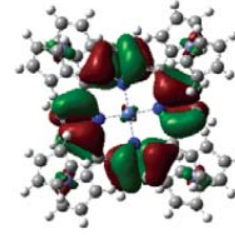

(266)

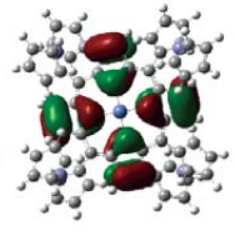

(264)

Fig. 9 Selected molecular orbitals of the NiTFcP complex predicted at DFT level using the BPW91 exchange-correlation functional. 

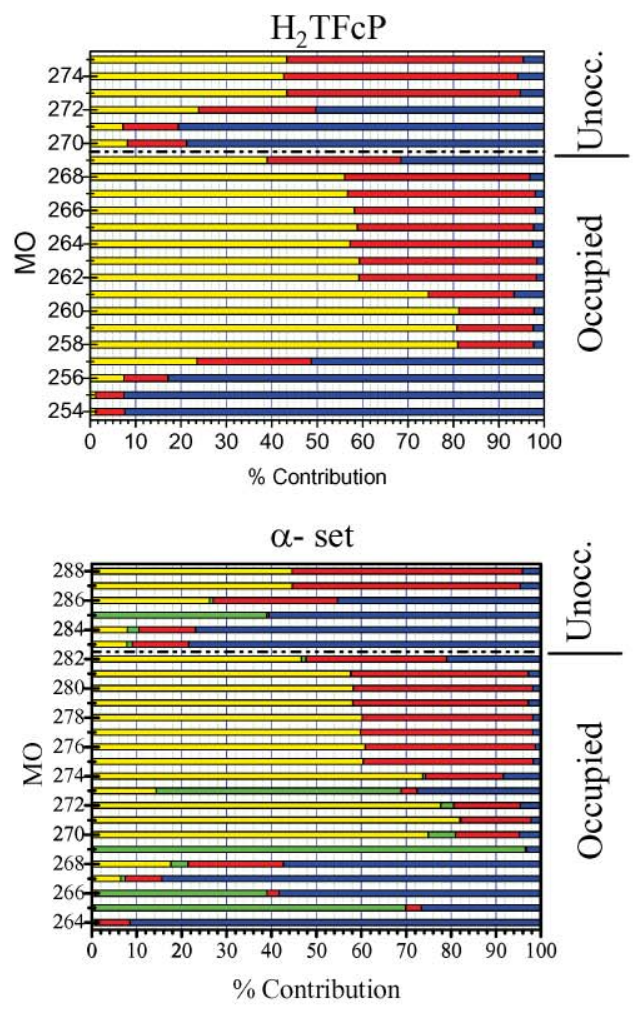

CoTFcP
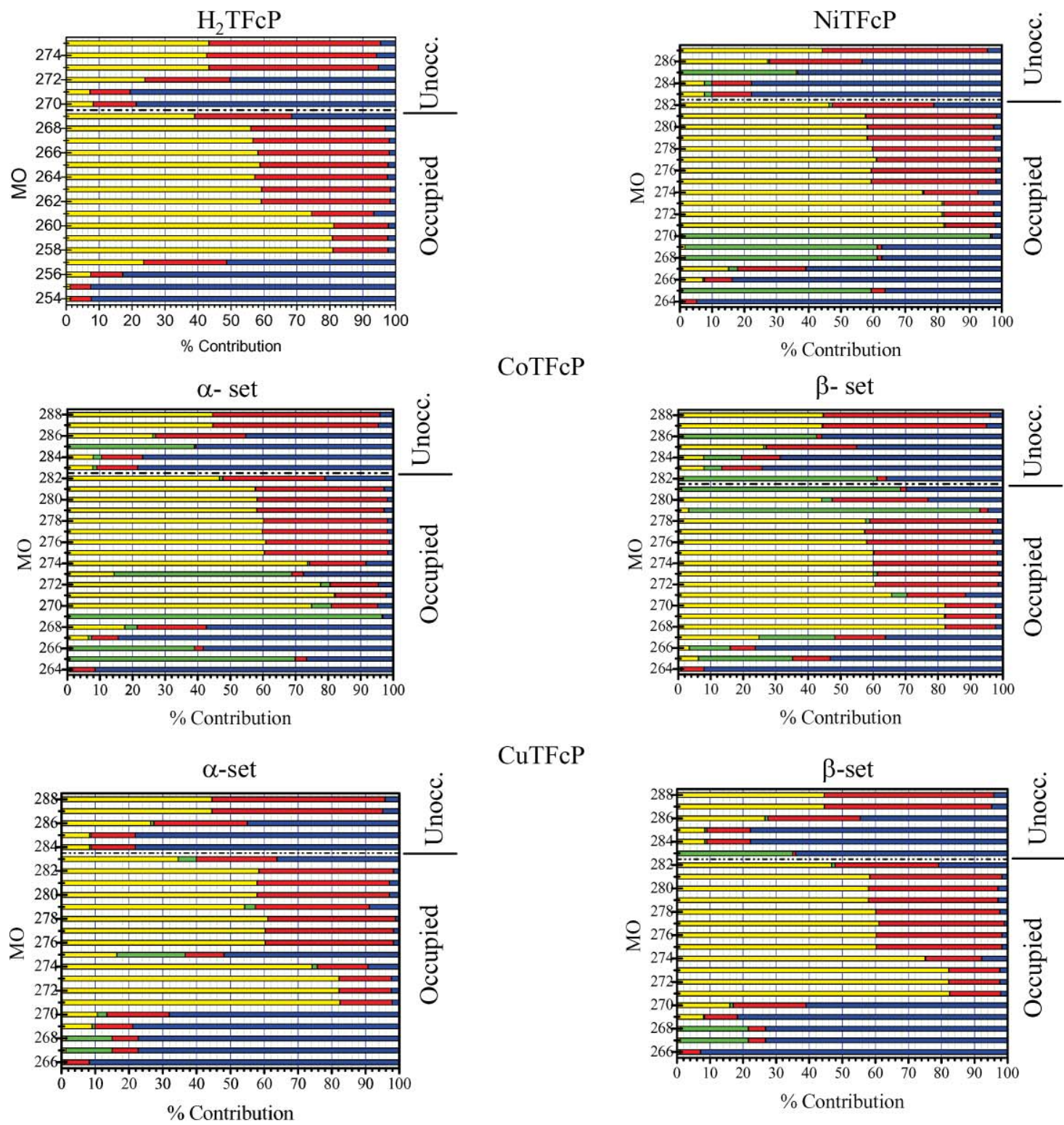

CuTFcP
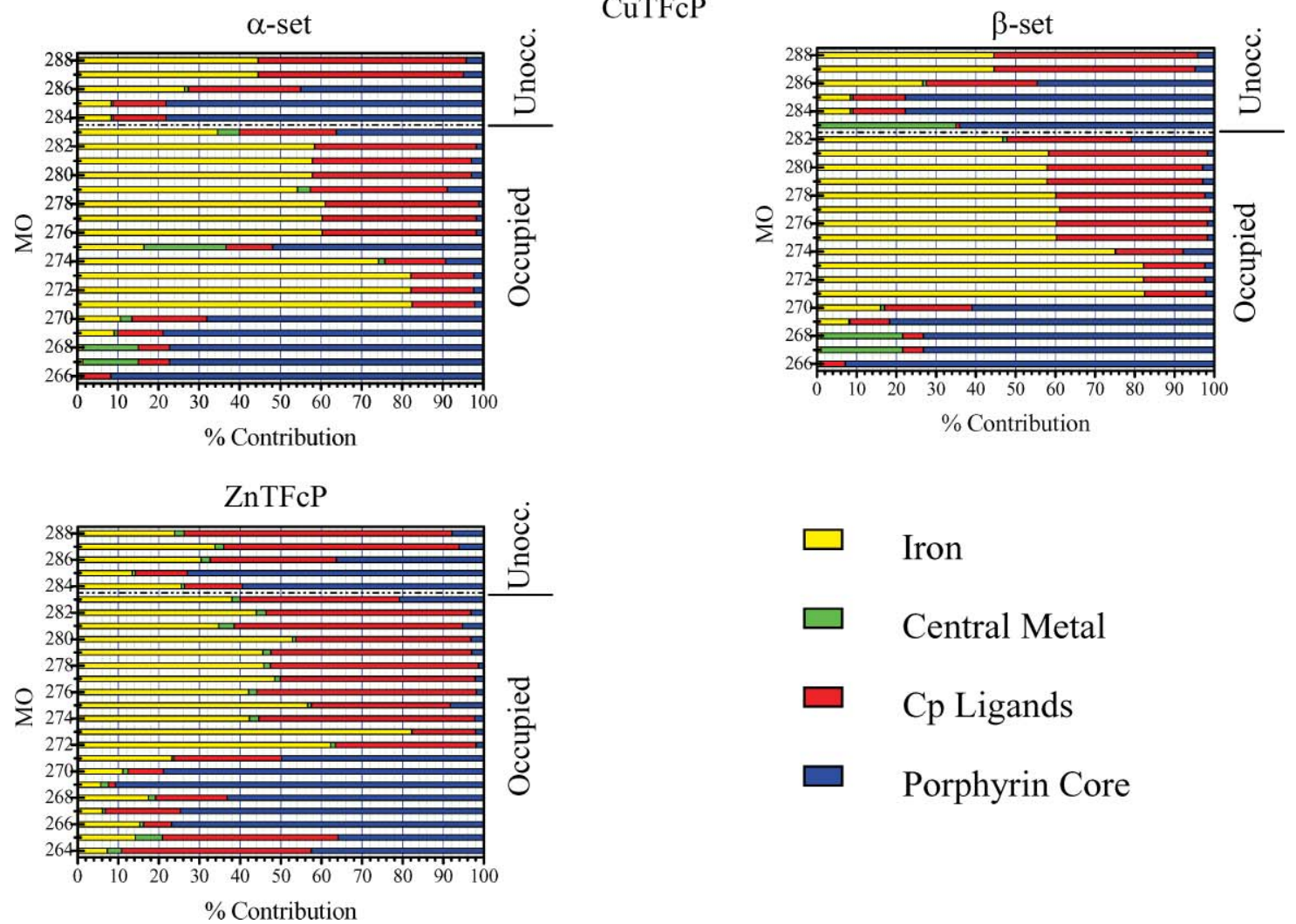

\section{Iron}

Central Metal

Cp Ligands

Porphyrin Core

Fig. 10 Molecular orbital compositions in $\mathrm{H}_{2} \mathrm{TFcP}$ and MTFcP complexes. 


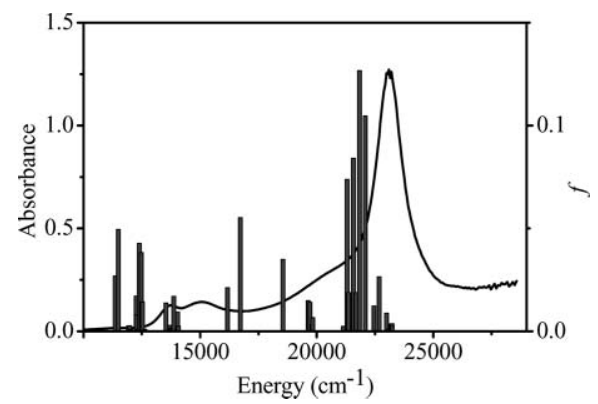

Fig. 11 Vertical excitation energies of the $\mathrm{H}_{2} \mathrm{TFcP}$ complex predicted using a TDDFT approach and a BPW91 exchange-correlation functional plotted over the experimental spectrum in $\mathrm{CHCl}_{3}$.

orbitals 258-269 (HOMO). This suggests that these bands cannot be purely described as the intra-ligand porphyrin based $\pi-\pi^{*}$ transitions. Thus, the majority of transitions predicted by the TDDFT method for $\mathrm{H}_{2}$ TFcP have predominantly MLCT origins. This situation is very different from the classic Gouterman's fourorbital model, ${ }^{50}$ which describes both Q- and Soret-band regions as pure $\pi-\pi^{*}$ transitions. Overall, although UV-vis and MCD spectra of $\mathrm{H}_{2} \mathrm{TFcP}$ and MTFcP complexes look similar to those observed in respective tetraaryl-porphyrins, the origin of these transitions is predominantly MLCT in the former and $\pi-\pi^{*}$ in the latter case, which is a very unusual situation in porphyrin chemistry. ${ }^{35}$ Since detailed assignment of the transitions observed in UV-vis and MCD spectra of $\mathrm{H}_{2} \mathrm{TFcP}$ and MTFcP complexes requires band deconvolution analysis and TDDFT data, we will provide a more detailed discussion on this subject in a separate paper.

\section{Conclusions}

$\mathrm{H}_{2} \mathrm{TFcP}[\mathrm{TFcP}=5,10,15,20$-tetraferrocenyl porphyrin(2-)] was prepared by a direct tetramerization reaction between pyrrole and ferrocene carbaldehyde in the presence of $\mathrm{BF}_{3}$ as catalyst, while a series of $\mathrm{MTFcP}(\mathrm{M}=\mathrm{Zn}, \mathrm{Ni}, \mathrm{Co}$ and $\mathrm{Cu})$ were prepared by a metallation reaction between $\mathrm{H}_{2} \mathrm{TFcP}$ and respective metal acetates. All compounds were characterized by UVvis and MCD spectroscopy, APCI MS and MS/MS methods, high-resolution ESI MS and XPS spectroscopy. Diamagnetic compounds were additionally characterized by ${ }^{1} \mathrm{H}$ and ${ }^{13} \mathrm{C}$ NMR, while the presence of low-spin iron(II) centers in the neutral compounds was confirmed by Mössbauer spectroscopy and by the analysis of the XPS Fe $2 \mathrm{p}$ peaks, revealing equivalent $\mathrm{Fe}$ sites. XPS additionally showed the influence on Fe $2 p$ binding energies exerted by the distinct central metal ions. The conformational flexibility of ferrocene substituents in $\mathrm{H}_{2} \mathrm{TFcP}$ and MTFcP, was proven by variable-temperature NMR and by computational methods. Density functional theory predicts that $\alpha, \beta, \alpha, \beta$-atropisomers with a ruffled porphyrin core conformation represents minima on the potential energy surfaces of both $\mathrm{H}_{2}$ TFcP and MTFcP. The degree of non-planarity depends on the central metal ion and follows the trend: $\mathrm{ZnTFcP}<\mathrm{H}_{2} \mathrm{TFcP} \sim$ $\mathrm{CuTFcP}<\mathrm{CoTFcP}<\mathrm{NiTFcP}$. In all the cases tested, the set of occupied, predominantly ferrocene-based molecular orbitals was found between the highest occupied and the lowest unoccupied, predominantly porphyrin-based molecular orbitals. The vertical excitation energies of $\mathrm{H}_{2} \mathrm{TFcP}$ were calculated at the TDDFT level and confirm the presence of numerous predominantly metal-to-ligand charge-transfer bands coupled via a configurational interaction, with expected intra-ligand $\pi-\pi^{*}$ transitions.

\section{Experimental}

\section{Materials}

All reactions were performed under a dry nitrogen atmosphere with flame-dried glassware. Pyrrole, ferrocenecarbaldehyde, benzaldehyde, boron trifluoride etherate, chloranil and triethylamine were purchased from commercially available sources and used without further purification.

Physical measurements. NMR spectra were recorded using a Varian INOVA instrument with $500 \mathrm{MHz}$ frequency for protons and $125 \mathrm{MHz}$ for carbon. Chemical shifts are reported in parts per million and are referenced to TMS as the internal standard. UV-vis data were obtained using a HP 8453 or Cary 17 spectrometers. MCD data were recorded using an OLIS DCM 17 CD spectropolarimeter using a $1.4 \mathrm{~T}$ DeSa magnet. The spectra were recorded twice for each sample, once with a parallel field and again with an antiparallel field, and their intensities were expressed by molar ellipticity per $\mathrm{T}=[\Theta]_{\mathrm{M}} / \mathrm{deg} \mathrm{dm}^{3} \mathrm{~mol}^{-1} \mathrm{~cm}^{-1} \mathrm{~T}^{-1}$. APCI-MS, APCI-MS/MS and LC-MS experiments were conducted using a Finnegan LCQ LC-MS system. High-resolution mass spectra were obtained using a Bruker HRMS instrument. Mössbauer spectra were recorded using a NGRS-4M spectrometer in constant acceleration mode. The source was ${ }^{57} \mathrm{Co}$ in a chromium matrix with an initial activity of $50 \mathrm{mCi}$. The isomer shifts are referenced against the $\alpha-\mathrm{Fe}$ at $298 \mathrm{~K}$.

XPS measurements. The solid compounds were ground into fine grains in an agate mortar, and the powder homogeneously spread over a conductive adhesive tape or a graphite sheet (in the case of $\mathrm{CuTFcP}$ ) and attached to a stainless steel XPS sample holder.

Photoelectron spectra have been acquired using a modified Omicron NanoTechnology MXPS system equipped with a dual X-ray anode source (Omicron DAR 400) and an Omicron EA127 hemispherical energy analyzer operated in constant analyzer energy (CAE) mode, with a pass energy of $20 \mathrm{eV}$. Al Ka ( $h v=$ $1486.6 \mathrm{eV})$ and $\mathrm{Mg} \mathrm{K} \alpha$ photons $(h v=1253.6 \mathrm{eV})$ were used to excite photoemission, operating at $14-15 \mathrm{kV}, 10-20 \mathrm{~mA}$. Data fitting with commercially available routines was applied using linear or Shirley backgrounds and linear combinations of Lorentzian and Gaussian lineshapes in order to determine full widths at half maximum (FWHM) and binding energies (BE) of the relevant core lines. Correction for static charging ( $\sim 2 \mathrm{eV}$ ) was done by referencing the BE to the ring carbon $\mathrm{C} 1 \mathrm{~s}$ peak, taken at $285.0 \mathrm{eV}$. The accuracy of reported BE is $\pm 0.2 \mathrm{eV}$ and the reproducibility of the results is within these values. XPS atomic ratios for the investigated compounds have been estimated from experimentally determined area ratios of core lines, after subtraction of background, removal of X-ray satellite peaks (deriving from the $\mathrm{K} \alpha_{3,4}$ components of the nonmonochromatic photon sources ${ }^{51}$ ), normalization for the atomic cross-section values and correction for an inverse dependence of the square root of kinetic energies. The contribution from shake-up satellites, accompanying main ionization peaks for metal 
cations, were added to the parent peak area. Atomic ratios are associated with an error of $\pm 15 \%$. In the case of CoTFcP, the Co $2 p$ photoelectron signal is overlapped with $\mathrm{Fe}_{2} \mathrm{M}_{4,5} \mathrm{M}_{4,5}$ Auger lines, as shown in Fig. 4-6, where the free base and CoTFcP signals are compared. The contribution of the $\mathrm{Fe}_{2} \mathrm{~L}_{4,5} \mathrm{M}_{4,5}$ Auger line was separated with data fitting, allowing for the correct calculation of the atomic ratios in CoTFcP, as reported in Table 3.

\section{Synthesis}

\section{$\mathbf{5 , 1 0 , 1 5 , 2 0 - t e t r a f e r r o c e n y l p o r p h y r i n . . ~}$}

(a) Direct reaction between pyrrole and ferrocenecarbaldehyde. This reaction was conducted following an earlier described synthetic procedure. ${ }^{21}$ Yield $40 \%$.

(b) Synthesis using 5-ferrocenyldipyrromethane as a precursor. 5 -ferrocenyldipyrromethane was prepared in $83 \%$ yield, adapting the literature procedure for substituted dipyrromethanes, ${ }^{28,52}$ ferrocenecarbaldehyde $2.92 \mathrm{~g}(13.6 \mathrm{mmol})$, pyrrole $38 \mathrm{~mL}(0.54 \mathrm{~mol})$ and trifluoroacetic acid (TFA) $0.11 \mathrm{~mL}$ (1.36 mmol), under an inert atmosphere. After classical ${ }^{52}$ workup and purification (column chromatography: silica gel, $40-70{ }^{\circ} \mathrm{C}$ petroleum ether with $7 \% \mathrm{v} / \mathrm{v}$ ethyl acetate), 5-ferrocenyldipyrromethane $0.5 \mathrm{~g}$ $(1.5 \mathrm{mmol})$ was reacted one of two ways. In the first reaction the 5-ferrocenyldipyrromethane was reacted with ferrocenecarboxyaldehyde $0.32 \mathrm{~g},(1.5 \mathrm{mmol})$ in dry dichloromethane $(150 \mathrm{~mL})$ with $p$-toluenesulfonic acid $(0.1$ molar equivalents, $0.15 \mathrm{mmol})$ and the reaction was stirred in dark for $90 \mathrm{~min}$. Then chloranil $0.37 \mathrm{~g}$ ( $1.5 \mathrm{mmol})$ was added and the reaction was refluxed for $90 \mathrm{~min}$ in air. In the other procedure, a solution of 5ferrocenyldipyrromethane $0.52 \mathrm{~g}(1.5 \mathrm{mmol})$ in dry $\mathrm{CH}_{2} \mathrm{Cl}_{2}$ $(150 \mathrm{~mL})$ was stirred for $5 \mathrm{~min}$ in the dark. Trifluoroacetic acid $(60 \mu \mathrm{L})$ was added and the reaction was stirred for an additional $90 \mathrm{~min}$. Then chloranil $0.39 \mathrm{~g}(1.5 \mathrm{mmol})$ was added and the reaction was refluxed in air for $90 \mathrm{~min}$. Better yields were obtained from the latter procedure (see Scheme 1). UV-vis $\left(\lambda_{\max } / \mathrm{nm}, \mathrm{CHCl}_{3}\right.$, $\left.\varepsilon \times 10^{-4}\right): 434$ (12.1), $485 \mathrm{sh}, 661$ (1.73), 726 (1.53). ${ }^{1} \mathrm{H}-\mathrm{NMR}$ $\left(\mathrm{CDCl}_{3}, \mathrm{TMS}, \delta\right): 9.61$ (s, 8H, $\beta$-pyrr), 5.32 (m, 8H, $\left.\alpha-\mathrm{Cp}\right), 4.75$ $(\mathrm{m}, 8 \mathrm{H}, \beta-\mathrm{Cp}), 3.97$ (s, 20H, CpH), -0.49 (s, 2H, NH). ${ }^{13} \mathrm{C}-$ NMR $\left(\mathrm{CDCl}_{3}\right.$, TMS, $\left.\delta\right), 145.8$ ( $\alpha$-Pyrr), 130.6 ( $\beta$-Pyrr), 117.1 $\left(\mathrm{C}_{\text {meso }}\right), 88.9\left(\mathrm{Cp}_{\text {ipso }}\right), 76.6(\alpha-\mathrm{Cp}), 70.1(\mathrm{CpH}), 68.8(\beta-\mathrm{Cp})$. MS (APCI, THF, $m / z): 1047.13(100 \%)[\mathrm{M}+\mathrm{H}]^{+}$. HRMS (ESI, THF, $m / z$ ): 1047.1193, calcd for $\mathrm{C}_{60} \mathrm{H}_{47} \mathrm{~N}_{4} \mathrm{Fe}_{4}: 1047.1200$, calcd for $\mathrm{C}_{60} \mathrm{H}_{46} \mathrm{~N}_{4} \mathrm{Fe}_{4}$ : C 68.87, $\mathrm{H} \mathrm{4.43,} \mathrm{N} \mathrm{5.35 \% .} \mathrm{Found:} \mathrm{C} \mathrm{68.74,} \mathrm{H}$ $4.48, \mathrm{~N} 4.81 \%$.

Zinc 5,10,15,20-tetra(ferrocenyl)porphyrin. A mixture of $\mathrm{H}_{2} \mathrm{TFcP}(0.0314 \mathrm{~g}, 0.03 \mathrm{mmol})$ and zinc acetate $(0.05 \mathrm{~g}, 0.3 \mathrm{mmol})$ in benzene $(25 \mathrm{ml})$ was refluxed for $2 \mathrm{~h}$. After solvent evaporation, the residue was subjected to chromatography on alumina oxide using benzene as the eluent. Yield $0.028 \mathrm{~g}(83 \%)$. UV-vis $\left(\lambda_{\max } / \mathrm{nm}\right.$, $\left.\mathrm{CHCl}_{3}, \varepsilon \times 10^{-4}\right): 320$ (3.42), 435 (14.3), $485 \mathrm{sh}, 620 \mathrm{sh}, 681$ (3.15). ${ }^{1} \mathrm{H}-\mathrm{NMR}\left(\mathrm{CDCl}_{3}\right.$, TMS, $\delta$ ): 9.84 (s, 8H, $\beta$-pyrr), 5.37 (m, 8H, $\alpha-$ $\mathrm{Cp}), 4.80$ (m, 8H, $\beta-\mathrm{Cp}), 4.07$ (s, 20H, CpH). ${ }^{13} \mathrm{C}-\mathrm{NMR}\left(\mathrm{CDCl}_{3}\right.$, TMS, $\delta), 148.9$ ( $\alpha$-Pyrr), 131.6 ( $\beta$-Pyrr), $118.2\left(\mathrm{C}_{\text {meso }}\right), 90.1\left(\mathrm{Cp}_{\text {ipso }}\right)$, $77.1(\alpha-\mathrm{Cp}), 70.3(\mathrm{CpH}), 68.7$ ( $\beta$-Cp). MS (APCI, THF, $m / z)$ : $1108[\mathrm{M}+1]^{+}$, calcd for $\mathrm{C}_{60} \mathrm{H}_{44} \mathrm{~N}_{4} \mathrm{Fe}_{4} \mathrm{Zn}$ : C 64.93, H 4.00, N 5.05, Zn 5.89\%. Found: C 64.29, H 4.31, N 5.13, Zn 5.42\%. A similar reaction of $\mathrm{H}_{2} \mathrm{TFcP}$ and $\mathrm{Zn}(\mathrm{OAc})_{2}$ in $\mathrm{CHCl}_{3}$ (reflux) or $\mathrm{CH}_{2} \mathrm{Cl}_{2}$ (room temperature) leads to the formation of $\mathrm{ZnTFcP}$ with yields of $57 \%$ and $25 \%$, respectively.
Nickel 5,10,15,20-tetra(ferrocenyl)porphyrin. A mixture of $\mathrm{H}_{2}$ TFcP (105 mg, $0.1 \mathrm{mmol}$ ) and nickel acetate tetrahydrate (360 mg, $1.0 \mathrm{mmol})$ in DMF $(25 \mathrm{ml})$ was heated for $2 \mathrm{~h}$ at $100{ }^{\circ} \mathrm{C}$. The reaction was poured into water and the precipitate was filtered and dried in air. The residue was subjected to chromatography on silica-gel using toluene as the eluent. Yield $0.052 \mathrm{~g}(47 \%)$. UV-vis $\left(\lambda_{\max } / \mathrm{nm}, \mathrm{CHCl}_{3}, \varepsilon \times 10^{-4}\right): 320 \mathrm{sh}, 329$ (5.07), 430 (15.0), 485 sh, 591 (1.92), 681 (3.88), 800 sh. ${ }^{1} \mathrm{H}-\mathrm{NMR}$ $\left(\mathrm{CDCl}_{3}, \mathrm{TMS}, \delta\right): 9.38$ (s, 8H, $\beta$-pyrr), 5.07 (m, 8H, $\left.\alpha-\mathrm{Cp}\right), 4.66(\mathrm{~m}$, $8 \mathrm{H}, \beta-\mathrm{Cp}$ ), 3.94 (s, 20H, CpH). MS (APCI, THF, $m / z$ ): $1103[\mathrm{M}]^{+}$. HRMS (ESI, THF, $m / z$ ): 1102.0331, calcd for $\mathrm{C}_{60} \mathrm{H}_{44} \mathrm{~N}_{4} \mathrm{Fe}_{4} \mathrm{Ni}$ : 1102.0312, calcd for $\mathrm{C}_{60} \mathrm{H}_{44} \mathrm{~N}_{4} \mathrm{Fe}_{4} \mathrm{Ni}$ : C 65.33, H 4.02, N 5.08\%. Found: $\mathrm{C} 68.63, \mathrm{H} \mathrm{4.52,} \mathrm{N} \mathrm{5.02 \%}$. A similar reaction of $\mathrm{H}_{2} \mathrm{TFcP}$ and $\mathrm{Ni}(\mathrm{OAc})_{2}$ in $\mathrm{CHCl}_{3}$ (reflux) leads to the formation of $\mathrm{NiTFcP}$ in $29 \%$ yield.

Cobalt 5,10,15,20-tetra(ferrocenyl)porphyrin. A mixture of $\mathrm{H}_{2}$ TFcP (105 mg, $0.1 \mathrm{mmol}$ ) and cobalt acetate hexahydrate (453 mg, $1.0 \mathrm{mmol})$ in DMF $(25 \mathrm{ml})$ was heated for $2 \mathrm{~h}$ at $100{ }^{\circ} \mathrm{C}$. The reaction was poured into water and the precipitate was filtered and dried in air. The residue was subjected to chromatography on silica-gel using toluene as the eluent. Yield $0.031 \mathrm{~g}(28 \%)$. UV-vis $\left(\lambda_{\max } / \mathrm{nm}, \mathrm{CHCl}_{3}, \varepsilon \times 10^{-4}\right): 320(6.65)$, 420 (13.4), $490 \mathrm{sh}, 660$ (3.04), $590 \mathrm{sh}, 800 \mathrm{sh}$. MS (APCI, THF, $m / z): 1136\left[\mathrm{M}+\mathrm{O}_{2}+\mathrm{H}\right]^{+}$. HRMS (ESI, THF, $\left.m / z\right):[\mathrm{M}]^{+}$ 1103.0280, $[\mathrm{M}+\mathrm{O}+\mathrm{H}]^{+}$1120.0367, $\left[\mathrm{M}+\mathrm{O}_{2}+\mathrm{H}\right]^{+}$1135.0145, calcd for $\mathrm{C}_{60} \mathrm{H}_{44} \mathrm{~N}_{4} \mathrm{Fe}_{4} \mathrm{Co}$ : 1103.0290 , calcd for $\mathrm{C}_{60} \mathrm{H}_{45} \mathrm{~N}_{4} \mathrm{Fe}_{4} \mathrm{CoO}$ : 1120.0318, calcd for $\mathrm{C}_{60} \mathrm{H}_{45} \mathrm{~N}_{4} \mathrm{Fe}_{4} \mathrm{CoO}_{2}: 1135.0188$, calcd for $\mathrm{C}_{60} \mathrm{H}_{44} \mathrm{~N}_{4} \mathrm{Fe}_{4} \mathrm{Co}$ : C 65.32, $\mathrm{H}$ 4.02, N 5.08\%. Found: $\mathrm{C} 68.68, \mathrm{H}$ $4.52, \mathrm{~N} \mathrm{5.41 \%}$. A similar reaction of $\mathrm{H}_{2} \mathrm{TFcP}$ and $\mathrm{Co}(\mathrm{OAc})_{2}$ in $\mathrm{CHCl}_{3}$ (reflux) leads to the formation of CoTFcP in $79 \%$ yield.

Copper 5,10,15,20-tetra(ferrocenyl)porphyrin. A mixture of $\mathrm{H}_{2}$ TFcP (105 mg, $\left.0.1 \mathrm{mmol}\right)$ and copper acetate hexahydrate (458 mg, $1.0 \mathrm{mmol})$ in DMF $(25 \mathrm{ml})$ was heated for $2 \mathrm{~h}$ at $100{ }^{\circ} \mathrm{C}$. The reaction was poured into water and the precipitate was filtered and dried in air. The residue was subjected to chromatography on silica-gel using toluene as the eluent. Yield $0.031 \mathrm{~g}(28 \%)$. UV-vis $\left(\lambda_{\max } / \mathrm{nm}, \mathrm{CHCl}_{3}, \varepsilon \times 10^{-4}\right): 314(5.19), 430$ (20.2), 500 sh, 600 sh, 669 (2.92). Calcd for $\mathrm{C}_{60} \mathrm{H}_{44} \mathrm{~N}_{4} \mathrm{Fe}_{4} \mathrm{Cu}: \mathrm{C}$ 65.04, H 4.00, N 5.06\%. Found: C 68.32, H 4.46, N 4.99\%.

\section{Computational Aspects}

All DFT calculations were conducted using the Gaussian 03 software package running under either Windows or UNIX OS. ${ }^{53} \mathrm{~A}$ spin-unrestricted method was used for all paramagnetic complexes under consideration. The molecular geometries were optimized using Becke's three-parameter hybrid exchange functional ${ }^{54}$ and Lee-Yang-Parr non-local correlation functional ${ }^{55}$ (B3LYP) level coupled with Wachter's full-electron and 6-31G(d) basis sets for iron and all other atoms, respectively. For all optimized structures, frequency calculations were carried out to ensure optimized geometries represented local minima. In the case of single point calculations, for all compounds, Becke's pure exchange functional ${ }^{56}$ and Perdew and Wang's ${ }^{57}$ correlation functional (BPW91) were used. Wachter's full-electron basis set (contracted as 62111111/3311111/3111) with one set of polarization functions ${ }^{58}$ was used for the iron atom, while for all other atoms 6-311G(d) ${ }^{59}$ basis set was employed. In all cases the ultra fine 
integral grid with 99 radial shells and 590 angular points per shell has been used. Finally tight energy $\left(10^{-8} \mathrm{au}\right) \mathrm{SCF}$ convergence criterion has been used. The Mössbauer quadrupole splittings $\left(\Delta E_{\mathrm{Q}}\right)$ and asymmetry parameters $(\eta)$ were calculated using the DFT predicted principle components of the electric field gradient tensor $\left(V_{\text {ii }}\right)$ at the ${ }^{57} \mathrm{Fe}$ nucleus as discussed earlier. ${ }^{47}$

TDFDT calculations were performed using the Gaussian 03 software with the same exchange-correlation functional and basis sets as indicated for Mössbauer parameters calculations. The first 60 excitations were taken into consideration in order to ensure coverage of the Soret band region of the UV-vis spectrum of $\mathrm{H}_{2}$ TFcP.

The rotational barriers of the ferrocenyl moieties were calculated using HyperChem 7.5 Pro software ${ }^{60}$ at the semi-empirical PM3 level. ${ }^{61}$ In one series of calculations, one torsion angle, C ( $\alpha$-Pyrr)$\mathrm{C}_{\text {mess }}(\mathrm{Por})-\mathrm{C}_{\text {ipso }}(\mathrm{Fc})-\mathrm{C}(\alpha-\mathrm{Cp})$, was changed in $10^{\circ}$ increments, while the other part of the molecule remained fixed (this approach is mentioned as 'rigid'). In the other series of calculations, one torsion angle, $\mathrm{C}(\alpha-\mathrm{Pyrr})-\mathrm{C}_{\text {meso }}(\mathrm{Por})-\mathrm{C}_{\text {ipso }}(\mathrm{Fc})-\mathrm{C}(\alpha-\mathrm{Cp})$, was changed in $10^{\circ}$ increments, while the other part of molecule was fully optimized (this approach is mentioned as 'relaxed'). Then the height of rotation barrier was derived from the variation of total energy as a function of the rotation angle.

\section{Acknowledgements}

Generous support from the NSF (CHE-0809203) Research Corporation (Cottrell College Science Award CC6766), University of Minnesota Grant-in-Aid (Grant 20209) and Minnesota Supercomputing Institute to $\mathrm{VN}$ as well as University of Minnesota Duluth Undergraduate Research Opportunity Grants to RH and $\mathrm{CB}$ is greatly appreciated. We also wish to thank Dr N. Kobayashi for the possibility to collect preliminary MCD data on $\mathrm{H}_{2} \mathrm{TFcP}$ and ZnTFcP, Dr E. Polshin for help with Mössbauer experiments, Dr R. Belosludov for help with TDDFT calculations, Dr A. Oyler for help with APCI spectra and Dr A. Koposov for help with NMR spectroscopy.

\section{References}

1 J. R. Heath and M. A. Ratner, Phys. Today, 2003, 56, 43-49; J. Chen, T. Lee, J. Su, W. Wang and M. A. Reed, Encyclopedia of Nanoscience and Nanotechnology, 2004, 5, 633-662.

2 W. Kaim and G. K. Lahiri, Angew. Chem., Int. Ed., 2007, 46, 17781796; W. Kaim and B. Sarkar, Coord. Chem. Rev., 2007, 251, 584-594; M. H. Chisholm and N. J. Patmore, Acc. Chem. Res., 2007, 40, 19-27; E. I. Solomon, R. Sarangi, J. S. Woertink, A. J. Augustine, J. Yoon and S. Ghosh, Acc. Chem. Res., 2007, 40, 581-591.

3 J. S. Miller and A. J. Epstein, Angew. Chem., Int. Ed. Engl., 1994, 33, $385-415$.

4 A. J. Epstein and J. S. Miller, Synth. Met., 1996, 80, 231-237.

5 S. Barlow and D. O'Hare, Chem. Rev., 1997, 97, 637-669.

6 S. Barlow, Inorg. Chem., 2001, 40, 7047-7053.

7 D. O. Cowan and F. Kaufman, J. Am. Chem. Soc., 1970, 92, 6198-6204.

8 D. O. Cowan and F. Kaufman, J. Am. Chem. Soc., 1970, 92, 219-220.

9 W. H. Morrison, Jr. and D. N. Hendrickson, Chem. Phys. Lett., 1973, 22, 119-23.

10 W. H. Morrison, Jr., S. Krogsrud and D. N. Hendrickson, Inorg. Chem., 1973, 12, 1998-2004.

11 W. H. Morrison, Jr. and D. N. Hendrickson, Inorg. Chem., 1975, 14, 2331-2346.

12 T. Y. Dong and D. N. Hendrickson, Bull. Inst. Chem. Acad. Sinica, 1987, 34, 67-75.
13 L. M. Tolbert, X. Zhao, Y. Ding and L. A. Bottomley, J. Am. Chem. Soc., 1995, 117, 12891-12892.

14 A.-C. Ribou, J.-P. Launay, M. L. Sachtleben, H. Li and C. W. Spangler, Inorg. Chem., 1996, 35, 3735-3740.

15 C. Patoux, C. Coudret, J.-P. Launay, C. Joachim and A. Gourdon, Inorg. Chem., 1997, 36, 5037-5049.

16 Q. Li, G. Mathur, S. Gowda, S. Surthi, Q. Zhao, L. Yu, J. S. Lindsey, D. F. Bocian and V. Misra, Adv. Mater., 2004, 16, 133-137.

17 A. K. Burrell, W. M. Campbell, G. B. Jameson, D. L. Officer, P. D. W. Boyd, Z. Zhao, P. A. Cocks and K. C. Gordon, Chem. Commun., 1999, 637-638.

18 S. W. Rhee, Y. H. Na, Y. Do and J. Kim, Inorg. Chim. Acta, 2000, 309, 49-56.

19 A. Auger and J. Swarts, Organometallics, 2007, 26, 102-109.

20 A. Auger, A. J. Muller and J. C. Swarts, Dalton Trans., 2007, 3623-3633.

21 V. N. Nemykin, C. D. Barrett, R. G. Hadt, R. I. Subbotin, A. Y. Maximov, E. V. Polshin and A. Y. Koposov, Dalton Trans., 2007, 33783389.

22 V. N. Nemykin, M. Mc Ginn, A. Y. Koposov, I. N. Tretyakova, E. V. Polshin, N. M. Loim and N. V. Abramova, Ukr. Khim. Zh. (Russ. Ed.), 2005, 71, 79-85.

23 V. A. Nadtochenko, D. V. Khudyakov, N. V. Abramova, E. V. Vorontsov, N. M. Loim, F. E. Gostev, D. G. Tovbin, A. A. Titov and O. M. Sarkisov, Russ. Chem. Bull., 2002, 51, 986-993.

24 P. Galloni, B. Floris, L. de Cola, E. Cecchetto and R. M. Williams, J. Phys. Chem. C: Condens. Matter, 2007, 111, 1517-1523.

25 K.-L. C. Cheng, H.-W. Li and D. K. P. Ng, J. Organomet. Chem., 2004, 689, 1593-1598; M. C. Hodgson, A. K. Burrell, P. D. W. Boyd, P. J. Brothers and C. E. F. Rickard, J. Porphyrins phthalocyanines, 2002, 6, 737-747; K.-W. Poon, W. Liu, P.-K. Chan, Q. Yang, T.-W. D. Chan, T. C. W. Mak and D. K. P. Ng, J. Org. Chem., 2001, 66, 1553-1559.

26 R. G. Wollmann and D. N. Hendrickson, Inorg. Chem., 1977, 16, 30793089.

27 N. M. Loim, N. V. Abramova and V. I. Sokolov, Mendeleev Commun., 1996, 46-47.

28 S. J. Narayanan, S. Venkatraman, S. R. Dey, B. Sridevi, V. R. G. Anand and T. K. Chandrashekar, Synlett, 2000, 1834-1836.

29 J. S. Lindsey and R. W. Wagner, J. Org. Chem., 1989, 54, 828-836.

30 M. Castagnola, B. Floris, G. Illuminati and G. Ortaggi, J. Organomet. Chem., 1973, 60, C17-C18; M. A. R. Bramley, J. Upadhyay, A. Wassermann and P. Woolliams, Chem. Commun. (London), 1965, 404 406; J. Silver, J. Chem. Soc., Dalton Trans., 1990, 3513-3516.

31 J. I. Kaplan and G. Fraenkel, NMR of chemically exchanging systems, Academic Press, New York, USA, 1980, pp. 71-129.

32 (a) H. García-Ortega, J. Crusats, M. Feliz and J. M. Ribó, J. Org. Chem., 2002, 67, 4170-4176; (b) M. J. Crossley, L. D. Field, M. M. Harding and S. J. Sternhell, J. Am. Chem. Soc., 1987, 109, 2335-2341; (c) M. J. Crossley, M. M. Harding and S. J. Sternhell, J. Am. Chem. Soc., 1986, 108, 3608-3613.

33 (a) J. Hennig and H.-H. Limbach, J. Chem. Soc., Faraday Trans. 2, 1979, 75, 752-766; (b) S. S. Eaton and G. R. Eaton, J. Am. Chem. Soc., 1977, 99, 1601-1604.

$34 \mathrm{H}$. Friebolin, Basic one- and two-dimensional NMR spectroscopy, Wiley-VCH, Weinheim, Germany, 4th edn, 2005, pp. 305-334.

35 J. Cheek, J. H. Dawson, in: Porphyrin Handbook, ed. K. M. Kadish, K. M. Smith and R. Guillard, Academic Press, San Diego, CA, USA, 2000, vol. 7, 339-369.

36 Y. Niwa, H. Kobayashi and T. Tsuchiya, Inorg. Chem., 1974, 13, 28912896; D. Karweik, N. Winograd, D. G. Davis and K. M. Kadish, J. Am. Chem. Soc., 1974, 98, 591-592; M. Seno, S. Tsuchiya and S. Ogawa, J. Am. Chem. Soc., 1977, 99, 3014-3018; J. P. Macquet, M. M. Millard and T. Theophanides, J. Am. Chem. Soc., 1978, 100, 4741-4746; K. Tatsumi and M. Tsutsui, J. Am. Chem. Soc., 1980, 102, 882-884; P. G. Gassman, A. Ghosh and J. Almloef, J. Am. Chem. Soc., 1992, 114, 9990-10000; L. Scudiero, D. E. Barlow and K. W. Hipps, J. Phys. Chem. B, 2000, 104, 11899-11905; C. Berrìos, G. I. Càrdenas-Jiròn, J. F. Marco, C. Gutiérrez and M. S. Ureta-Zañartu, J. Phys. Chem. A, 2007, 111, 2706-2714.

37 R. Zanoni, A. Aurora, F. Cattaruzza, F. Decker, P. Fastigi, V. Menichetti, P. Tagliatesta, A.-L. Capodilupo and A. Lembo, Mater. Sci. Eng., C, 2007, 27, 1351-1354.

38 Y. Niwa, H. Kobayashi and T. Tsuchiya, J. Chem. Phys., 1974, 60, 799-807.

39 H. Murai, M. Torres and O. P. Strausz, J. Am. Chem. Soc., 1980, 102, 5106-5107. 
40 G. Bar, S. Rubin, T. N. Taylor, B. I. Swanson, T. A. Zawodzinski Jr., J. T. Chow and J. P. Ferraris, J. Vac. Sci. Technol., A, 1996, 14, 1794-1800; C. M. Woodbridge, D. L. Pugmuir, R. C. Johnson, N. M. Boag and M. A. Langell, J. Phys. Chem. B, 2000, 104, 3085-3093; R. Zanoni, F. Cattaruzza, C. Coluzza, E. A. Dalchiele, F. Decker, G. Di Santo, A. Flamini, L. Funari and A. G. Marrani, Surf. Sci., 2005, 575, 260-272; B. Fabre and F. Hauquier, J. Phys. Chem. B, 2006, 110, 6848-6855; F. Decker, F. Cattaruzza, C. Coluzza, A. Flamini, A. G. Marrani, R. Zanoni and E. A. Dalchiele, J. Phys. Chem. B, 2006, 110, 7374-7379.

41 J. K. M. Sanders, N. Bampos, Z. Clyde-Watson, S. L. Darling, J. C. Hawley, H.-J. Kim, C. C. Mak and S. J. Webb, in Porphyrin Handbook, ed. K. M. Kadish, K. M. Smith and R. Guilard, Academic Press, San Diego, CA, USA, 2000, vol. 3, pp. 1-48.

42 I. M. Ruzic, T. D. Smith and J. R. Pilbrow, J. Chem. Soc., Dalton Trans. 1982, 373-380

43 (a) V. N. Nemykin and P. Basu, Inorg. Chim. Acta, 2005, 358, 28762882; (b) V. N. Nemykin and P. Basu, Dalton Trans., 2004, 1928-1933; (c) C. P. G. Butcher, P. J. Dyson, B. F. G. Johnson, T. Khimyak and J. S. McIndoe, Chem.-Eur. J., 2003, 9, 944-950; (d) E. Crawford, P. J. Dyson, O. Forest, S. Kwok and J. S. McIndoe, J. Cluster Sci., 2006, 17, $47-63$.

44 (a) G. J. Van Berkel, S. A. McLuckey and G. L. Glish, Anal. Chem., 1991, 63, 1098-1109; (b) M. R. M. Domingues, M. G. O. S.- Marques, P. Domingues, M. G. Neves, J. A. S. Cavaleiro, A. J. Ferrer-Correia, O. V. Nemirovskiy and M. L. Gross, J. Am. Soc. Mass Spectrom., 2001, 12, 381-384; (c) K. S. F. Lau, M. Sadilek, M. Gouterman, G. E. Khalil and C. Brückner, J. Am. Soc. Mass Spectrom., 2006, 17, 1306-1314; (d) V. V. Serra, M. R. M. Domingues, M. A. F. Faustino, P. Domingues, J. P. C. Tomé, M. G. P. M. S. Neves, A. C. Tomè, J. A. S. Cavaleiro and A. J. Ferrer-Correia, Rapid Commun. Mass Spectrom., 2005, 19, 2569-2580.

45 S. A. Borisenkova, E. P. Denisova, E. A. Batanova, E. G. Girenko, O. L. Kaliya, E. A. Lukyanets and G. N. Vorozhtsov, J. Porphyrins phthalocyanines, 2000, 4, 684-688; M.-J. Lin, L. Yang and J.-D. Wang, J. Mol. Catal. A: Chem., 2007, 273, 156-159; D. Kumar, S. P. de Visser and S. Shaik, J. Am. Chem. Soc., 2005, 127, 8204-8213.

46 E. Fluck, in Chemical Applications of Mössbauer Spectroscopy, ed. V. I. Goldanskii, R. H. Herber, Academic Press, Inc., New York, 1968, 268.

47 V. N. Nemykin and R. G. Hadt, Inorg. Chem., 2006, 45, 8297-8307.

48 C. Garino, R. Gobetto, C. Nervi, L. Salassa, E. Rosenberg, J. B. A Ross, X. Chu, K. I. Hardcastle and C. Sabatini, Inorg. Chem., 2007, 46, 8752-8762; F. Wang and T. Ziegler, J. Chem. Phys., 2005, 123, 194102/1-194102/10; M. Seth and T. Ziegler, J. Chem. Phys., 2005, 123, 144105/1-144105/14; V. N. Nemykin, E. A. Makarova, J. O.
Grosland, R. G. Hadt and A. Y. Koposov, Inorg. Chem., 2007, 46, 9591-9601; V. N. Nemykin, A. Y. Maximov and A. Y. Koposov, Organometallics, 2007, 26, 3138-3148; V. N. Nemykin, J. G. Olsen, E. Perera and P. Basu, Inorg. Chem., 2006, 45, 3557-3568; V. N. Nemykin and P. Basu, Inorg. Chem., 2003, 42, 4046-4056.

49 A. Rosa, G. Ricciardi, E. J. Baerends, M. Zimin, M. A. J. Rodgers, S. Matsumoto and N. Ono, Inorg. Chem., 2005, 44, 6609-6622; L. Petit, A. Quartarolo, C. Adamo and N. Russo, J. Phys. Chem. B, 2006, 110, 2398-2404; V. N. Nemykin, R. G. Hadt, R. V. Belosludov, H. Mizuseki and Y. Kawazoe, J. Phys. Chem. A, 2007, 111, 12901-12913.

50 M. Gouterman, in Porphyrins ed. D. Dolphin, Academic, New York, 1978, vol. 3, pp. 1-165.

51 D. Briggs and M. P. Seah, Practical Surface Analysis, J. Wiley, \& Sons, Chichester, vol. 1, 2nd edn, 1990.

52 B. J. Littler, M. A. Miller, C.-H. Hung, R. W. Wegner, D. F. O'Shea, P. D. Boyle and J. S. Lindsey, J. Org. Chem., 1999, 64, 1391-1396.

53 M. J. Frisch, G. W. Trucks, H. B. Schlegel, G. E. Scuseria, M. A. Robb, J. R. Cheeseman, J. A. Montgomery, Jr., T. Vreven, K. N. Kudin, J. C. Burant, J. M. Millam, S. S. Iyengar, J. Tomasi, V. Barone, B. Mennucci, M. Cossi, G. Scalmani, N. Rega, G. A. Petersson, H. Nakatsuji, M. Hada, M. Ehara, K. Toyota, R. Fukuda, J. Hasegawa, M. Ishida, T. Nakajima, Y. Honda, O. Kitao, H. Nakai, M. Klene, X. Li, J. E. Knox, H. P. Hratchian, J. B. Cross, V. Bakken, C. Adamo, J. Jaramillo, R. Gomperts, R. E. Stratmann, O. Yazyev, A. J. Austin, R. Cammi, C. Pomelli, J. Ochterski, P. Y. Ayala, K. Morokuma, G. A. Voth, P. Salvador, J. J. Dannenberg, V. G. Zakrzewski, S. Dapprich, A. D. Daniels, M. C. Strain, O. Farkas, D. K. Malick, A. D. Rabuck, K. Raghavachari, J. B. Foresman, J. V. Ortiz, Q. Cui, A. G. Baboul, S. Clifford, J. Cioslowski, B. B. Stefanov, G. Liu, A. Liashenko, P. Piskorz, I. Komaromi, R. L. Martin, D. J. Fox, T. Keith, M. A. Al-Laham, C. Y. Peng, A. Nanayakkara, M. Challacombe, P. M. W. Gill, B. G. Johnson, W. Chen, M. W. Wong, C. Gonzalez and J. A. Pople, GAUSSIAN 03 (Revision C.02), Gaussian, Inc., Wallingford, CT, 2004.

54 A. D. Becke, Phys. Rev. A: At., Mol., Opt. Phys., 1988, 38, 3098-3100.

55 C. Lee, W. Yang and R. G. Parr, Phys. Rev. B: Condens. Matter Mater. Phys., 1988, 37, 785-789.

56 A. D. Becke, Phys. Rev. A: At., Mol., Opt. Phys., 1988, 38, 3098-3100.

57 J. P. Perdew and Y. Wang, Phys. Rev. B: Condens. Matter Mater. Phys., 1992, 45, 13244-13249.

58 A. J. H. Wachters, J. Chem. Phys., 1970, 52, 1033-1036.

59 A. D. McLean and G. S. Chandler, J. Chem. Phys., 1980, 72, 56395948; R. Krishnan, J. S. Binkley, R. Seeger and J. A. Pople, J. Chem. Phys., 1980, 72, 650-654.

60 HyperChem Pro, version 7.51, HyperCube, Inc., Gainesville, FL, 2004. 61 J. J. P. Stewart, J. Comput. Aided Mol. Des., 1990, 4, 1-105. 